Check for updates

Cite this: RSC Adv., 2018, 8, 39149

\title{
Synthesis and characterization of magnetic mesoporous $\mathrm{Fe}_{3} \mathrm{O}_{4} \mathrm{amSiO}_{2}-$ DODGA nanoparticles for adsorption of 16 rare earth elements $\dagger$
}

\author{
Jingrui Li, ${ }^{\text {ab }}$ Aijun Gong, (D) *ab Fukai Li, ${ }^{\text {ab }}$ Lina Qiu, ${ }^{\text {ab }}$ Weiwei Zhang, ${ }^{\text {ab }}$ Ge Gao, ${ }^{\text {ab }}$ \\ Yu Liu ${ }^{\text {ab }}$ and Jiandi Lib
}

\begin{abstract}
In this study, novel magnetic mesoporous $\mathrm{Fe}_{3} \mathrm{O}_{4} \mathrm{amSiO}_{2}-\mathrm{DODGA}$ nanoparticles were prepared for efficiently adsorbing and recycling REEs. $\mathrm{Fe}_{3} \mathrm{O}_{4}\left(\mathrm{amSiO}_{2}-\mathrm{DODGA}\right.$ was characterized by powder $\mathrm{X}$-ray diffraction (XRD), transmission electron microscopy (TEM), vibrating sample magnetometry (VSM), Fourier transform infrared spectroscopy (FT-IR) and thermogravimetric analysis (TGA). The adsorption behavior of $\mathrm{Fe}_{3} \mathrm{O}_{4}\left(\mathrm{amSiO}_{2}-\right.$ DODGA was investigated by ICP-OES. The results showed that the content of DODGA in the adsorbent was $367 \mu \mathrm{mol} \mathrm{g}{ }^{-1}$. $\mathrm{Fe}_{3} \mathrm{O}_{4} \mathrm{amSiO}_{2}$-DODGA exhibited the highest adsorption rates for 15 REEs, except Tm, in a $2 \mathrm{~mol} \mathrm{~L}^{-1}$ nitric acid solution. Among these elements, the adsorption rates for $\mathrm{Nd}, \mathrm{Sm}$, Eu, Dy, Ho, Yb, Lu, Y and Sc ranged from $85.1 \%$ to $100.1 \%$. The desorption rates for all 16 REE ions reached their maximum values when $0.01 \mathrm{~mol} \mathrm{~L}^{-1}$ EDTA was used as the eluent. The desorption rates for $\mathrm{Nd}, \mathrm{Ce}, \mathrm{Sm}, \mathrm{Eu}, \mathrm{Ho}, \mathrm{Yb}, \mathrm{Lu}, \mathrm{Y}$, and Sc were $87.7-99.8 \%$. Fe $\mathrm{O}_{4}\left(\mathrm{amSiO}_{2}-\mathrm{DODGA}\right.$ had high stability in $2 \mathrm{~mol} \mathrm{~L}^{-1} \mathrm{HNO}_{3}$ and could be used five times without significant loss of adsorption capacity. Moreover, these nanoparticles had high selectivity, and their adsorption rate was not affected even in a high-concentration solution of a coexisting ion. Therefore, 8 REE ions ( $\mathrm{Nd}, \mathrm{Sm}, \mathrm{Eu}, \mathrm{Ho}, \mathrm{Yb}, \mathrm{Lu}, \mathrm{Y}$, and Sc) were selected for the study of adsorption kinetics and adsorption isotherm experiments. It was demonstrated that the values of $Q_{\mathrm{e}}$ (equilibrium adsorption capacity) for $\mathrm{Nd}, \mathrm{Sm}$, $\mathrm{Eu}, \mathrm{Ho}, \mathrm{Yb}, \mathrm{Lu}, \mathrm{Y}$, and Sc were $14.28-60.80 \mathrm{mg} \mathrm{g}^{-1}$. The adsorption of REEs on $\mathrm{Fe}_{3} \mathrm{O}_{4} \mathrm{amSiO}{ }_{2}-\mathrm{DODGA}$ followed the pseudo-second-order kinetic model, Elovich model and Langmuir isotherm model, which indicated that the adsorption process of $\mathrm{Fe}_{3} \mathrm{O}_{4} \mathrm{amSiO}{ }_{2}$-DODGA for REEs comprised single-layer adsorption on a non-uniform surface controlled by chemical adsorption. It was concluded that $\mathrm{Fe}_{3} \mathrm{O}_{4}\left(\mathrm{amSiO}_{2}-\mathrm{DODGA}\right.$ represents a new material for the adsorption of REEs in strongly acidic solutions.
\end{abstract}

Received 18th September 2018 Accepted 2nd November 2018

DOI: $10.1039 / c 8 r a 07762 b$

rsc.li/rsc-advances separation and purification of REEs are still the main technical difficulties and need further industrial processes.

Therefore, many efforts have been made to develop efficient methods for extracting and purifying REEs, such as liquid-liquid extraction, ${ }^{4,5}$ supported liquid extraction ${ }^{6}$ or solid-phase extraction $^{7}$ procedures. These methods all rely on the association constants between ligands and REEs. Liquid-liquid extraction is the most widely used method. The most widely used ligands include di(2-ethylhexyl)phosphoric acid (HDEHP, P204), ${ }^{\mathbf{8} 9}$ 2-ethylhexylphosphonic acid mono(2-ethylhexyl) ester (HEHEHP, P507), ${ }^{10}$ and tributyl phosphate (TBP). ${ }^{11}$ Among the obvious disadvantages inherent in liquid-liquid extraction are the utilization of large volumes of solvents in the extraction procedure and the generation of undesired waste. Supported liquid extraction and solid-phase extraction are relatively environmentally friendly. The combination of a suitable solid phase and effective ligands represents one direction for the development of extraction methods for REEs. Inspired by the above description, nanosized materials are among the candidates for the solid phase. Nanosized materials (e.g., silica nanoparticles, ${ }^{12}$ carbon nanotubes, ${ }^{13}$ and magnetic nanoparticles ${ }^{\mathbf{1 4 , 1 5}}$ ) with a high surface
${ }^{a}$ School of Chemistry and Biological Engineering, University of Science and Technology Beijing, Beijing 100083, China. E-mail: Gongaijun5661@ustb.edu.cn; Fax: +86-1062334071; Tel: +86-10-82375661

${ }^{b}$ Beijing Key Laboratory for Science and Application of Functional Molecular and Crystalline Materials, University of Science and Technology Beijing, Beijing 100083, China

$\dagger$ Electronic supplementary information (ESI) available. See DOI: 10.1039/c8ra07762b 
area ratio have been utilized in various fields. ${ }^{16}$ In particular, magnetic nanoparticles are commonly considered for use as internal supporting materials in some fields for the following reasons: their easy preparation via solvothermal reactions and superparamagnetic features for fast separation from complex samples in practical applications. ${ }^{17}$ There are several kinds of magnetic solid-phase extraction material that are employed for the adsorption of a single REE such as Eu(III) and Ce(III) in an aqueous solution. These materials mainly include mesoporous SBA-15 modified with the Schiff base $N, N^{\prime}$-bis(salicylidene)-1,2ethylenediamine and decorated on $\mathrm{Fe}_{3} \mathrm{O}_{4}$ nanoparticles (SBA15-BSEA-Fe ${ }_{3} \mathrm{O}_{4}$-NPs), ${ }^{18}$ a Ce(III) ion-imprinted polymer (Ce(III)-IIP) grafted on $\mathrm{Fe}_{3} \mathrm{O}_{4}$ nanoparticles supported by SBA-15 mesopores ( $\mathrm{Fe}_{3} \mathrm{O}_{4} @$ @SBA-15-Ce(III)-IIP), ${ }^{19}$ a core-shell structured $\mathrm{Fe}_{3} \mathrm{O}_{4} @$ carboxymethylcellulose magnetic composite $\left(\mathrm{Fe}_{3} \mathrm{O}_{4} @ \mathrm{CMC}\right),{ }^{20}$ an $\mathrm{Fe}_{3} \mathrm{O}_{4}$ /sepiolite composite, ${ }^{21}$ an $\mathrm{Fe}_{3} \mathrm{O}_{4}$ @cyclodextrin magnetic composite $\left(\mathrm{Fe}_{3} \mathrm{O}_{4} @ \mathrm{CD}-\mathrm{MCs}\right)^{22}$ and core-shell structured $\mathrm{Fe}_{3}$ $\mathrm{O}_{4}$ @humic acid magnetic nanoparticles $\left(\mathrm{Fe}_{3} \mathrm{O}_{4} @ \mathrm{HA}-\mathrm{MNPs}\right) .{ }^{23}$

In addition, the ligand is also an important aspect of the design of solid-phase extraction materials. Among the ligands used for adsorbing REEs, $N, N, N^{\prime}, N^{\prime}$-tetraoctyldiglycolamide (TODGA) ${ }^{24,25}$ is among the ligands commonly used for separation. In this ligand, the functional group diglycolamide (DGA) plays an important role in coordination with REE ions. Some derivatives based on the DGA chemical structure have been synthesized and used industrially for adsorbing REEs and exhibited excellent enrichment and selectivity. ${ }^{\mathbf{2 6 , 2 7}}$ Unfortunately, no previous work has been published in which magnetic nanoparticles modified with a diglycolamide ligand were used for the adsorption of REEs. There have been reports on the synthesis of magnetic nanomaterials modified with diglycolamide ligands, including diglycolamic acid-functionalized chitosan-coated $\mathrm{Fe}_{3} \mathrm{O}_{4}$ (Fe@CSDGA $){ }^{28}$ TODGA-coated magnetite nanoparticles $\left(\mathrm{Fe}_{3} \mathrm{O}_{4}\right.$ @TODGA), ${ }^{29}$ and DGA-methacrylate-coated $\mathrm{Fe}_{3} \mathrm{O}_{4}$ particles ( $\mathrm{Fe}_{3} \mathrm{O}_{4} @ \mathrm{MC}$-DGA). ${ }^{30}$ However, these materials were employed for removing $\mathrm{Pb}$ (II) and extracting $\mathrm{Am}$ (III) and $\mathrm{Pu(IV)}$ in a nitric acid solution, but not for the adsorption of REEs.

In this study, mesoporous magnetic $\mathrm{Fe}_{3} \mathrm{O}_{4} @ \mathrm{mSiO}_{2}-$ DODGA nanomaterials were prepared by modifying the surface of mesoporous $\mathrm{Fe}_{3} \mathrm{O}_{4}$ particles with a diglycolamide ligand. In comparison with previously reported materials, 16 REEs other than the radioactive element Pm were used to assess the adsorption properties of the final products. Studies of the influence of coexisting ions and adsorption kinetics demonstrated that $\mathrm{Fe}_{3} \mathrm{O}_{4} @ \mathrm{mSiO}_{2}$-DODGA exhibited better anti-interference performance and a faster adsorption equilibrium process. Moreover, this highly selective $\mathrm{Fe}_{3} \mathrm{O}_{4}$ @$\mathrm{mSiO}_{2}$-DODGA exhibited high stability and reusability and represents a new solid-phase extraction material for the adsorption of rare earth elements under strongly acidic and high-salinity conditions.

\section{Experimental}

\subsection{Reagents and materials}

All reagents were of analytical grade unless otherwise noted. Stock solutions (1.000 $\mathrm{g} \mathrm{L}^{-1}$ ) of 16 REEs (La, Ce, Pr, Nd, Sm, Eu,
Gd, Td, Dy, Ho, Er, Tm, Yb, Lu, Y and Sc) were prepared by dissolving appropriate amounts of the corresponding Specpure oxides in dilute $\mathrm{HNO}_{3}$. Working solutions were prepared daily by appropriately diluting the stock solutions. $\mathrm{NaCl}, \mathrm{Na}_{2} \mathrm{SO}_{4}$, $\mathrm{FeCl}_{3}, \mathrm{AlCl}_{3}, \mathrm{CuSO}_{4}, \mathrm{ZnCl}_{2}, \mathrm{NaAc}, \mathrm{NaHCO}_{3}, \mathrm{NH}_{4} \mathrm{NO}_{3}, \mathrm{HNO}_{3}$, $\mathrm{H}_{2} \mathrm{O}_{2}, \mathrm{NH}_{3} \cdot \mathrm{H}_{2} \mathrm{O}, \mathrm{CH}_{2} \mathrm{Cl}_{2}$, ethanol, carbamide, ethylene glycol, acetic anhydride, oxalyl chloride and tetraethoxysilane (TEOS) were bought from Sinopharm Chemical Reagent Co., Ltd, China. Diglycolic acid, dioctylamine, cetyltrimethylammonium bromide (CTAB), and aminopropyltriethoxysilane (APTES) were purchased from Sigma-Aldrich Chemical Company. High-purity water $(18.2 \mathrm{M} \Omega \mathrm{cm})$ obtained from a Milli-Q Element system (Millipore, Molsheim, France) was used directly throughout this study. Plastic and glass containers and all other laboratory materials that could come into contact with the samples and standards were stored in $10 \%(\mathrm{v} / \mathrm{v})$ nitric acid for $24 \mathrm{~h}$ and rinsed with high-purity water.

\subsection{Material preparation}

Firstly, a magnetic recycling unit was constructed. Uniform $\mathrm{Fe}_{3} \mathrm{O}_{4}$ particles prepared via a solvothermal reaction (Scheme 1) ${ }^{\mathbf{3 1}}$ were chosen as the inner supporting materials, which were nanosized and had a much larger specific surface area and superparamagnetic properties. Secondly, amine groups were used to modify the surface of the $\mathrm{Fe}_{3} \mathrm{O}_{4}$ particles. ${ }^{32-34}$ Before this chemical modification, an $\mathrm{SiO}_{2}$ layer was coated efficiently on the $\mathrm{Fe}_{3} \mathrm{O}_{4}$ core to protect the $\mathrm{Fe}_{3} \mathrm{O}_{4}$ core from corrosion by the strong acid in the solution. A further mesoporous $\mathrm{SiO}_{2}$ layer was created on the surface of $\mathrm{Fe}_{3} \mathrm{O}_{4} @ \mathrm{SiO}_{2}$ to further modify the amino groups to prepare $\mathrm{Fe}_{3} \mathrm{O}_{4} @ \mathrm{mSiO}_{2} @ \mathrm{NH}_{2}$. The mesoporous structure increased the specific surface area of the material to enable modification with a greater amount of amino groups.

In the structure of TODGA, both carbonyl groups are bound to $N, N$-di(n-octyl)amine groups and have low reactivity. Therefore, $N, N$-dioctyldiglycolic acid (DODGA-OH) was synthesized. ${ }^{35,36}$ This compound has a highly active carboxylic acid group that can be converted into an acyl chloride (DODGA-Cl) and used to modify the magnetic core. In addition, DODGA$\mathrm{OH}$ retains half of the $n$-octyl substituents in TODGA, which ensures that the functional groups are hydrophobic. Finally, functional magnetic $\mathrm{Fe}_{3} \mathrm{O}_{4} @ \mathrm{mSiO}_{2}$-DODGA nanomaterials were obtained by modifying the diglycolamide functional unit DODGA-Cl with the aminated $\mathrm{Fe}_{3} \mathrm{O}_{4} @ \mathrm{mSiO}_{2} @ \mathrm{NH}_{2}$ particles.

\subsection{Characterization}

Characterization by Fourier transform infrared (FT-IR) spectroscopy was performed with an FT-IR 8400S spectrometer (Shimadzu, Japan). Spectra were recorded over the range of 4000-400 $\mathrm{cm}^{-1}$ in transmission mode, and 32 scans were accumulated at a resolution of $4 \mathrm{~cm}^{-1}$. Magnetic properties were determined with a 7410 vibrating sample magnetometer (VSM, Lake Shore Cryotronics, Inc., Ohio, USA). Morphological observations of the nanoparticles were carried out with a JEM2010 high-resolution transmission electron microscope (JEOL, Tokyo, Japan). Thermogravimetric analysis (TGA) was conducted using a Mettler Toledo TGA2 analyzer (Switzerland) from 


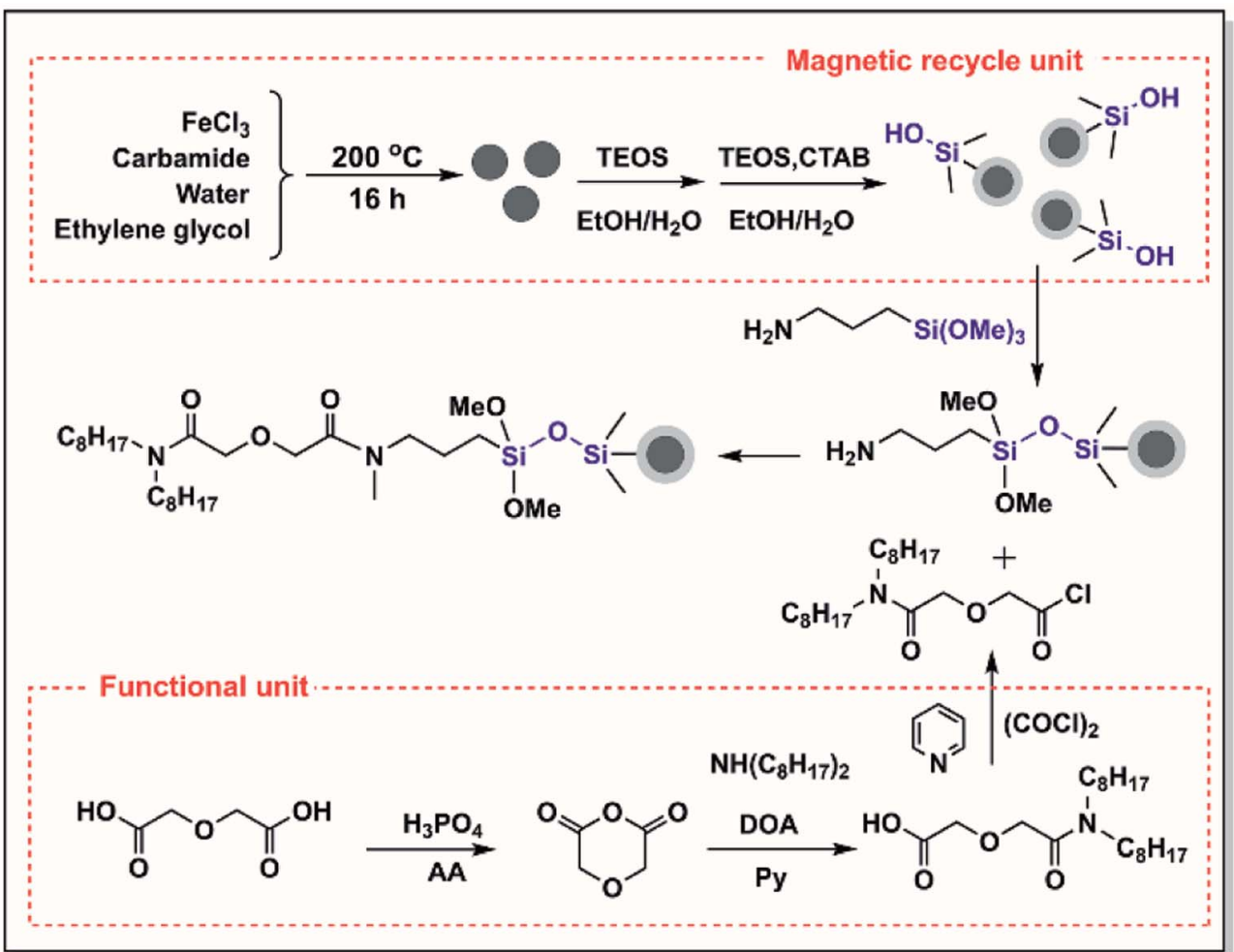

Scheme 1 Preparation of the functionalized $\mathrm{Fe}_{3} \mathrm{O}_{4}$ nanoparticles.

30 to $750{ }^{\circ} \mathrm{C}$ at a heating rate of $10{ }^{\circ} \mathrm{C} \mathrm{min}^{-1}$. X-ray diffraction (XRD) patterns were recorded in the range of $2 \theta=20-80^{\circ}$ by step scanning using a Rigaku D/Max-2500 diffractometer (Japan) with $\mathrm{Cu} \mathrm{K} \alpha$ radiation. ${ }^{1} \mathrm{H}$ NMR and ${ }^{13} \mathrm{C}$ NMR spectra were recorded with a Bruker AV-400 spectrometer with chemical shifts reported as ppm (in $\mathrm{CDCl}_{3}$ and DMSO- $\mathrm{d}_{6}$ with TMS as an internal standard). Mass spectrometric analysis was carried out using an LCQ Fleet mass spectrometer (Thermo Fisher). An ICPOES system (715-ES, Varian Medical Systems, USA) was used for the determination of REEs.
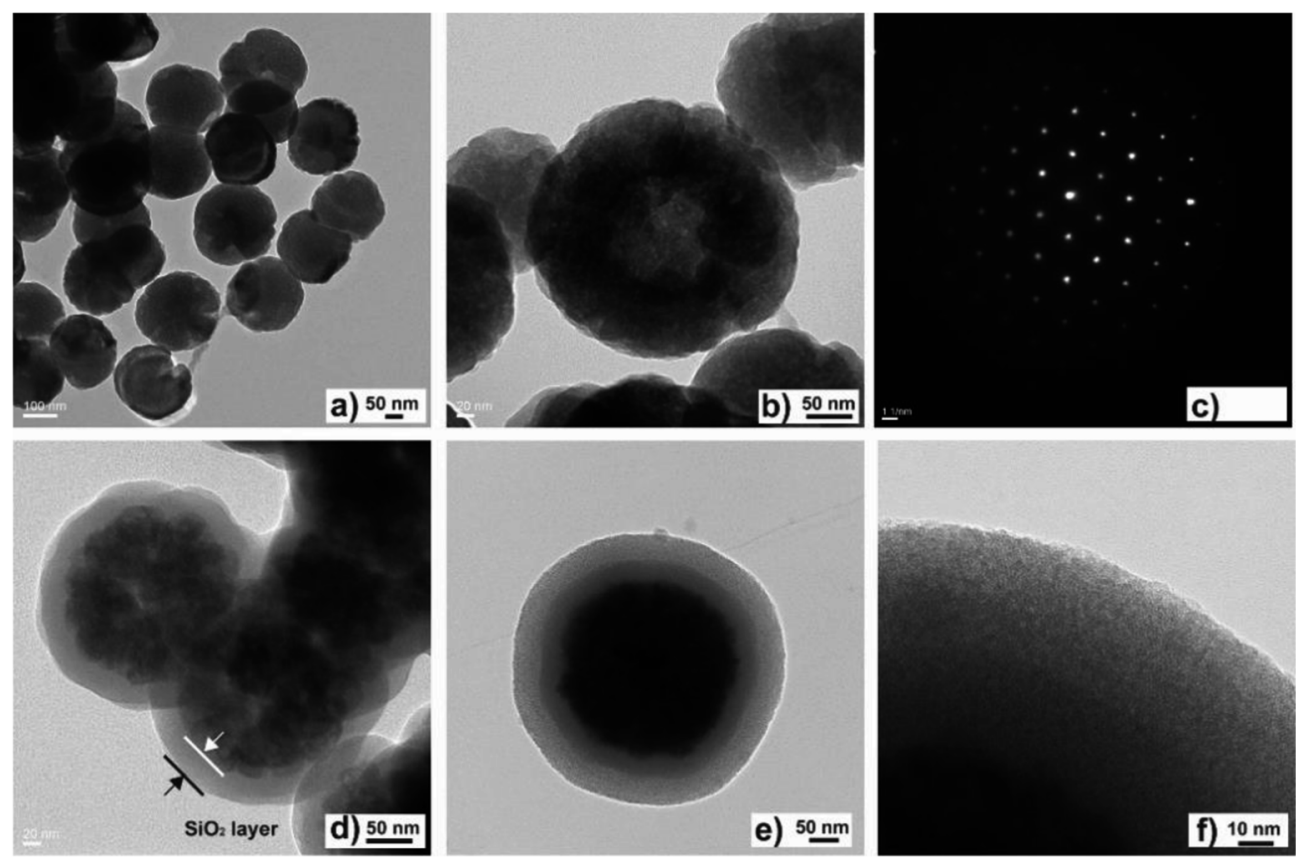

Fig. 1 TEM images of hollow $\mathrm{Fe}_{3} \mathrm{O}_{4}$ (a and b), SAED pattern (c), and TEM images of $\mathrm{Fe}_{3} \mathrm{O}_{4} \mathrm{aSiO}_{2}$ (d) and $\mathrm{Fe}_{3} \mathrm{O}_{4}\left(\mathrm{amSiO}_{2}\right.$ (e and f). 


\subsection{Adsorption experiments}

2.4.1 Effect of the concentration of $\mathrm{HNO}_{3}$ on the adsorption of REEs. Batch selection experiments on REEs were carried out in $10.0 \mathrm{~mL}$ glass tubes. To determine the optimum concentrations of $\mathrm{HNO}_{3}$ for the adsorption of REEs, the influence of the concentration of $\mathrm{HNO}_{3}$ was examined first. A series of REE solutions (containing 16 REEs; the concentration of each REE was $0.2 \mathrm{mg} \mathrm{L}^{-1}$ ) with different concentrations of $\mathrm{HNO}_{3}$ $\left(0.01,0.05,0.10,0.50,1.0,2.0\right.$, and $\left.3.0 \mathrm{~mol} \mathrm{~L}^{-1}\right)$ were prepared. Then, $10 \mathrm{mg}$ of $\mathrm{Fe}_{3} \mathrm{O}_{4} @ \mathrm{mSiO}_{2}$-DODGA nanoparticles was added to $10 \mathrm{~mL}$ of the REE solution under continuous stirring at $25{ }^{\circ} \mathrm{C}$ for $24 \mathrm{~h}$. The sorbent was separated with a magnet, and the content of rare earth ions in the supernatant was determined by ICP-OES.

2.4.2 Effect of the concentration of EDTA on the desorption of REEs. Multiple batches of $\mathrm{Fe}_{3} \mathrm{O}_{4} @ \mathrm{mSiO}_{2}-\mathrm{DODGA}$ nanoparticles loaded with rare earth ions were collected under the same conditions. A series of EDTA solutions $(0.002,0.005$, $0.01,0.02,0.03$, and $0.04 \mathrm{~mol} \mathrm{~L}^{-1}$ ) were used to desorb REEs from these $\mathrm{Fe}_{3} \mathrm{O}_{4} @ \mathrm{mSiO}_{2}$-DODGA nanoparticles under continuous stirring at $25{ }^{\circ} \mathrm{C}$ for $3 \mathrm{~h}$.
2.4.3 Stability of $\mathrm{Fe}_{3} \mathrm{O}_{4} @ \mathrm{mSiO}_{2}$-DODGA in $\mathrm{HNO}_{3} \cdot \mathrm{Fe}_{3^{-}}$ $\mathrm{O}_{4} @ \mathrm{mSiO}_{2}$-DODGA was soaked in $\mathrm{HNO}_{3}\left(2.0 \mathrm{~mol} \mathrm{~L}{ }^{-1}\right)$ for different numbers of days. The adsorption rates for 16 rare earth elements in mixed solutions were measured for different immersion times of the adsorbent, and their differences were compared.

2.4.4 Reusability of $\mathrm{Fe}_{3} \mathrm{O}_{4} @ \mathrm{mSiO}_{2}$-DODGA. To assess the recyclability of $\mathrm{Fe}_{3} \mathrm{O}_{4} @ \mathrm{mSiO}_{2}$-DODGA for the adsorption of REEs, 5 cycles of adsorption-desorption tests were conducted. For the desorption process, $\mathrm{Fe}_{3} \mathrm{O}_{4} @ \mathrm{mSiO}_{2}-$ DODGA loaded with REEs was washed with deionized water and then immersed in a $0.01 \mathrm{~mol} \mathrm{~L}^{-1}$ EDTA solution for $3 \mathrm{~h}$ after it was separated from the REE solution using a magnet. The adsorbent was washed with deionized water 3 times prior to the next adsorption cycle.

2.4.5 Effect of coexisting ions on the adsorption of REEs. The effect of coexisting ions was determined by adding the corresponding salts of model ions $\left(\mathrm{K}^{+}, \mathrm{Na}^{+}, \mathrm{Ca}^{2+}, \mathrm{Mg}^{2+}, \mathrm{Fe}^{3+}\right.$, $\mathrm{Al}^{3+}, \mathrm{Zn}^{2+}, \mathrm{Cu}^{2+}, \mathrm{SO}_{4}{ }^{2-}, \mathrm{Cl}^{-}$, and $\mathrm{NO}_{3}{ }^{-}$) to the solution of REEs.

2.4.6 Adsorption experiments. $\mathrm{Fe}_{3} \mathrm{O}_{4} @ \mathrm{mSiO}_{2}$-DODGA (20 $\mathrm{mg}$ ) was introduced into $100 \mathrm{~mL}$ solutions of single rare earth elements with an initial concentration $\left(C_{0}\right)$ of $20 \mathrm{mg} \mathrm{L}^{-1}$. The experiments were carried out in a water bath, and the solutions
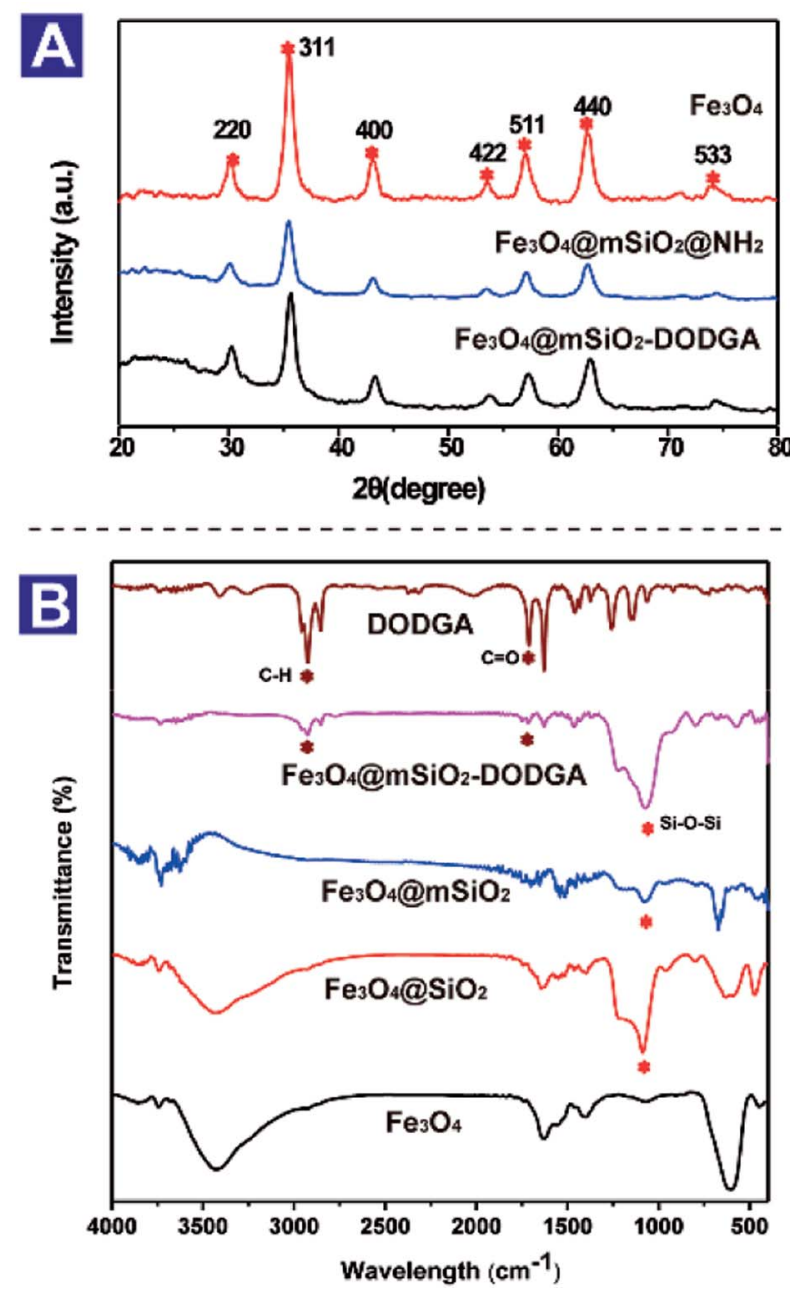
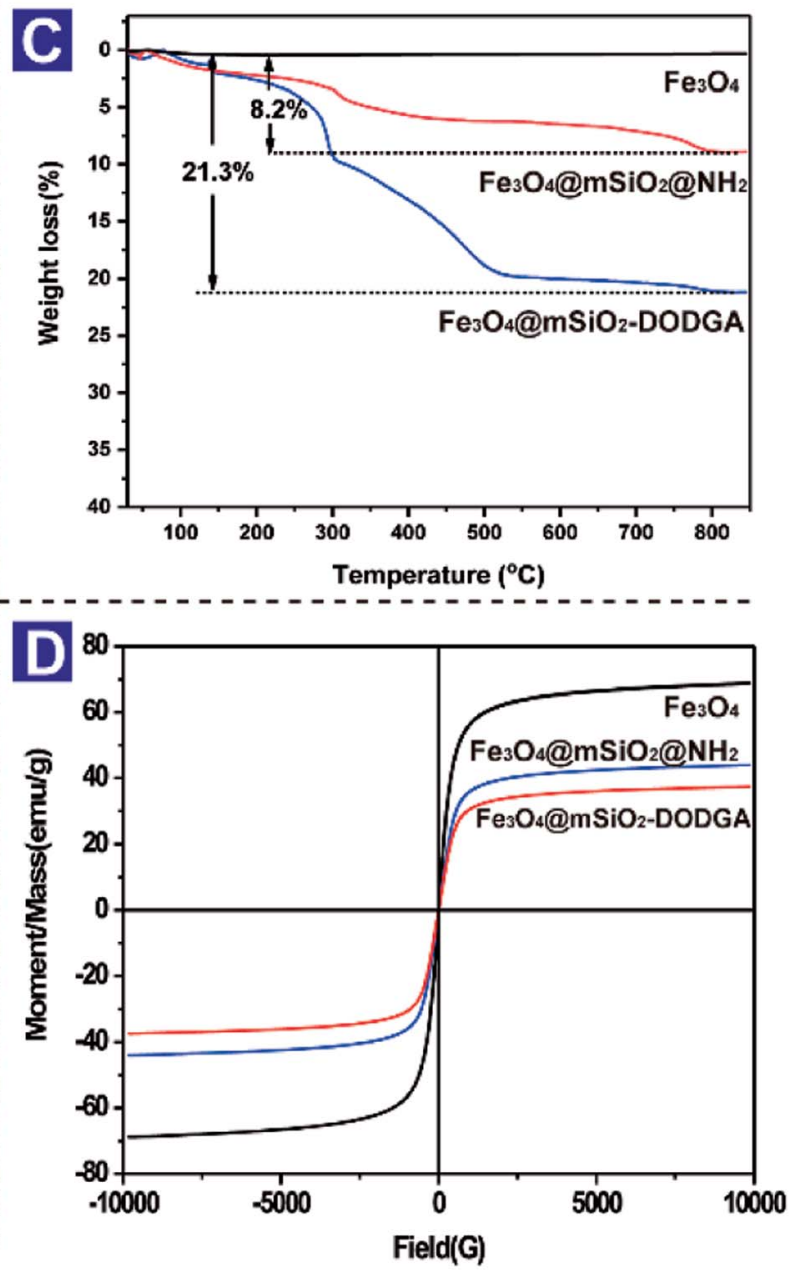

Fig. 2 XRD patterns (A), FT-IR spectra (B), TGA curves (C) and VSM curves (D) of $\mathrm{Fe}_{3} \mathrm{O}_{4}$ nanoparticles. 


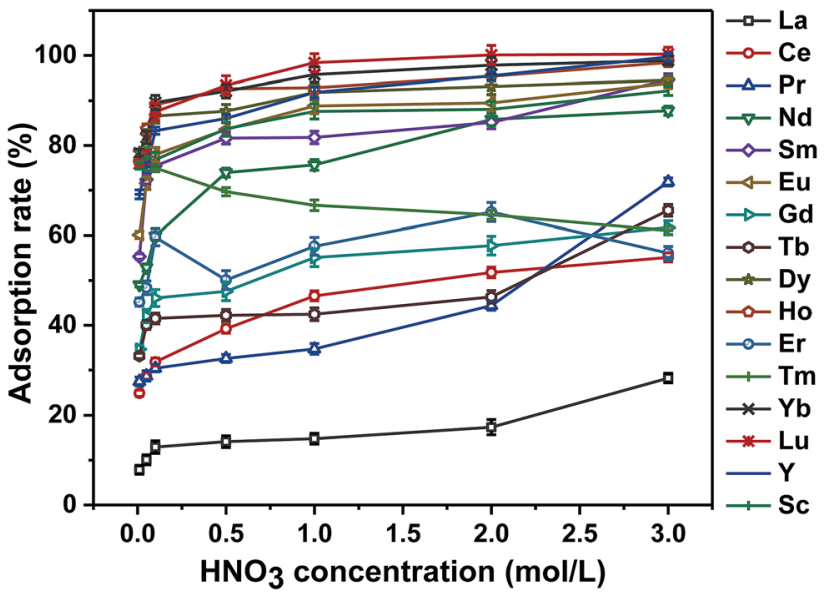

Fig. 3 Effect of different concentrations of $\mathrm{HNO}_{3}$ on the adsorption rate.

were stirred at $25{ }^{\circ} \mathrm{C}$. At certain time intervals (5, 10, 15, 30, 45, $60,120,240,360$, and $480 \mathrm{~min})$, the sorbent was separated with a magnet and the supernatant was analyzed to determine the remaining concentration $\left(C_{t}, \mathrm{mg} \mathrm{L}^{-1}\right)$ using ICP-OES.

Adsorption isotherms were calculated via batch experiments. The adsorbent was mixed with aqueous solutions containing different concentrations of 8 REEs ranging from 1 to $20 \mathrm{mg} \mathrm{L}^{-1}$ and stirred at $298 \mathrm{~K}$ for $24 \mathrm{~h}$. The sorbent was subsequently separated with a magnet, and the supernatant was analyzed to determine the remaining concentration $\left(C_{\mathrm{e}}, \mathrm{mg} \mathrm{L}^{-1}\right)$ using ICPOES.

\section{Results and discussion}

\subsection{Characterization of $\mathrm{Fe}_{3} \mathrm{O}_{4}, \mathrm{Fe}_{3} \mathrm{O}_{4} @ \mathrm{SiO}_{2}$, and $\mathrm{Fe}_{3} \mathrm{O}_{4} @ \mathrm{mSiO}_{2}-$ DODGA}

The morphological features of the nanomaterial were characterized by TEM to observe its specific shape and appearance characteristics. As shown in Fig. 1, the hollow $\mathrm{Fe}_{3} \mathrm{O}_{4}$ nanoparticles had spherical shapes and small sizes with a mean diameter of $200 \mathrm{~nm}$ (Fig. 1a and b). Single nanocrystals were analyzed by SAED, as shown in Fig. 1c. The diffraction patterns exhibited a distribution comprising a series of points, which was consistent with a face-centred crystal pattern, and the diffraction points corresponded to the (220) crystal planes of the

Table 1 Adsorption and desorption rates for 16 rare earth elements under optimal conditions

\begin{tabular}{llllll}
\hline Element & AR $(\%)$ & DR $(\%)$ & Element & AR (\%) & DR (\%) \\
\hline La & 17 & 17 & Dy & 93 & 67 \\
$\mathrm{Ce}$ & 52 & 94 & Ho & 95 & 98 \\
$\mathrm{Pr}$ & 44 & 45 & Er & 65 & 48 \\
$\mathrm{Nd}$ & 86 & 88 & Tm & 65 & 83 \\
$\mathrm{Sm}$ & 85 & 96 & Yb & 98 & 98 \\
Eu & 90 & 93 & Lu & 100 & 100 \\
$\mathrm{Gd}$ & 58 & 64 & $\mathrm{Y}$ & 95 & 99 \\
$\mathrm{~Tb}$ & 46 & 43 & $\mathrm{Sc}$ & 88 & 93
\end{tabular}

crystal. The layer of $\mathrm{SiO}_{2}$ was coated by a sol-gel reaction on the surface of the $\mathrm{Fe}_{3} \mathrm{O}_{4}$ particles. Under the same TEM characterization conditions as were used for the hollow $\mathrm{Fe}_{3} \mathrm{O}_{4}$ nanoparticles, the mean diameter of the $\mathrm{Fe}_{3} \mathrm{O}_{4} @ \mathrm{SiO}_{2}$ particles increased from $200 \mathrm{~nm}$ to $300 \mathrm{~nm}$. Well-defined core-shell structures can be clearly observed in a TEM image of $\mathrm{Fe}_{3} \mathrm{O}_{4}$ @a$\mathrm{SiO}_{2}$ particles (Fig. 1d). The core with dark contrast represented an $\mathrm{Fe}_{3} \mathrm{O}_{4}$ particle; the outer layer with light contrast represented the $\mathrm{SiO}_{2}$ shell. The outer layer of mesoporous silica was constructed by a sol-gel reaction with the help of the surfactant CTAB. The outer mesoporous $\mathrm{SiO}_{2}$ layer was lighter in color and looser in structure than the inner $\mathrm{SiO}_{2}$ layer (Fig. 1e and f). The construction of the mesoporous structure on $\mathrm{Fe}_{3} \mathrm{O}_{4}$ particles was carried out to increase the specific surface area of the material. To characterize the mesoporous structure, a BET experiment was performed. As shown in Fig. $\mathrm{S} 9, \dagger$ the pore diameter of $\mathrm{Fe}_{3} \mathrm{O}_{4} @ \mathrm{mSiO}_{2}-$ DODGA was about $6 \mathrm{~nm}$. Its specific surface area was $707.181 \mathrm{~m}^{2} \mathrm{~g}^{-1}$. In contrast, no pore structures existed in $\mathrm{Fe}_{3} \mathrm{O}_{4} @ \mathrm{SiO}_{2}$ (Fig. S10 ${ }^{\dagger}$ ). Its specific surface area was $16.284 \mathrm{~m}^{2} \mathrm{~g}^{-1}$, which was much smaller than that of $\mathrm{Fe}_{3} \mathrm{O}_{4}$ @$\mathrm{mSiO}_{2}-$ DODGA.

The crystal structure of $\mathrm{Fe}_{3} \mathrm{O}_{4}$ was characterized by XRD. The $\mathrm{X}$-ray diffraction pattern of $\mathrm{Fe}_{3} \mathrm{O}_{4}$ nanoparticles prepared via the solvothermal method exhibited six typical diffraction peaks corresponding to (220), (311), (400), (422), (511) and (440) planes. As shown in Fig. 2A, six peaks were observed by analyzing the $\mathrm{Fe}_{3} \mathrm{O}_{4}, \mathrm{Fe}_{3} \mathrm{O}_{4} @ \mathrm{mSiO}_{2}$ and $\mathrm{Fe}_{3} \mathrm{O}_{4} @ \mathrm{mSiO}_{2}-$ DODGA nanoparticles, which indicated that the crystal structure of the magnetite core was not changed by coating with the $\mathrm{SiO}_{2}$ or mesoporous silica layer or chemical modification with DODGA.

To characterize the chemical compositions of the bare $\mathrm{Fe}_{3} \mathrm{O}_{4}$ nanoparticles, $\mathrm{SiO}_{2^{-}}$and mesoporous silica-coated $\mathrm{Fe}_{3} \mathrm{O}_{4}$ nanoparticles, and DODGA-modified $\mathrm{Fe}_{3} \mathrm{O}_{4}$ nanoparticles, their FT-IR spectra were recorded, as shown in Fig. 2B. Firstly, an absorption band at $606 \mathrm{~cm}^{-1}$ attributed to the characteristic stretching vibrations of $\mathrm{Fe}-\mathrm{O}$ bonds in $\mathrm{Fe}_{3} \mathrm{O}_{4}$ appeared in the spectra of these nanoparticles, which indicated that the chemical structure of $\mathrm{Fe}_{3} \mathrm{O}_{4}$ was not changed by chemical modification. Owing to the coatings of $\mathrm{SiO}_{2}$ and mesoporous silica layers on the surface of the bare $\mathrm{Fe}_{3} \mathrm{O}_{4}$ nanoparticles, the strength of

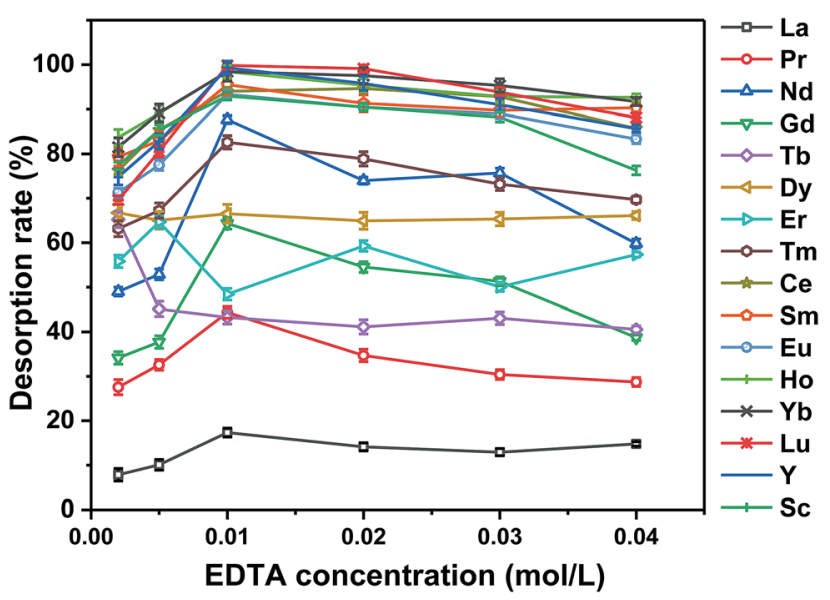

Fig. 4 Effect of EDTA concentration on desorption rate. 


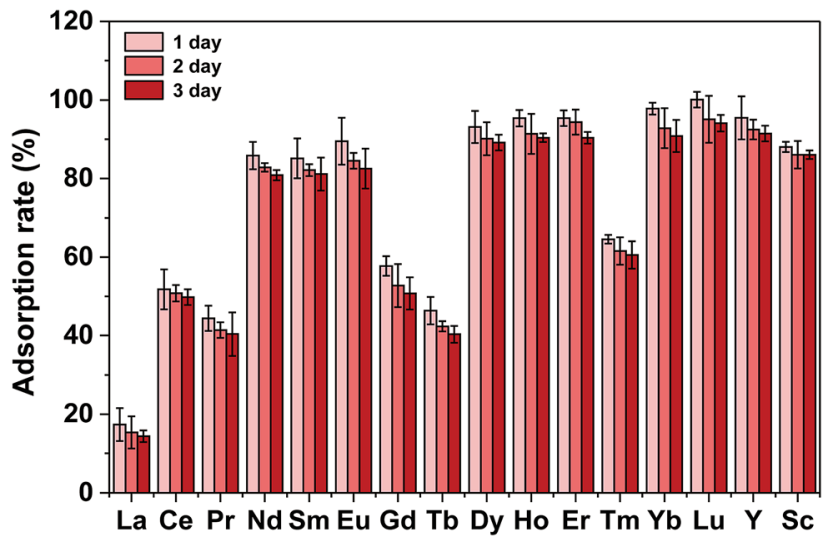

Fig. 5 Adsorption rates of $\mathrm{Fe}_{3} \mathrm{O}_{4}\left(\mathrm{amSiO}_{2}-\mathrm{DODGA}\right.$ after being immersed in an $\mathrm{HNO}_{3}$ solution for different numbers of days.

Table 2 Experimental results for reusability of $\mathrm{Fe}_{3} \mathrm{O}_{4}\left(\mathrm{amSiO}_{2}-\right.$ DODGA

\begin{tabular}{lrrrr}
\hline & \multicolumn{3}{l}{ Adsorption rate $(\%)$} & \\
\cline { 2 - 5 } Element & 1 & 2 & 3 & 4 \\
\hline $\mathrm{La}$ & 99 & 95 & 92 & 90 \\
$\mathrm{Ce}$ & 100 & 95 & 92 & 89 \\
$\mathrm{Pr}$ & 99 & 95 & 92 & 90 \\
$\mathrm{Nd}$ & 100 & 97 & 94 & 93 \\
$\mathrm{Sm}$ & 100 & 95 & 92 & 89 \\
$\mathrm{Eu}$ & 99 & 96 & 92 & 90 \\
$\mathrm{Gd}$ & 99 & 95 & 92 & 89 \\
$\mathrm{~Tb}$ & 99 & 93 & 90 & 89 \\
$\mathrm{Dy}$ & 100 & 96 & 92 & 89 \\
$\mathrm{Ho}$ & 100 & 95 & 92 & 90 \\
$\mathrm{Er}$ & 99 & 94 & 90 & 88 \\
$\mathrm{Tm}$ & 99 & 96 & 93 & 91 \\
$\mathrm{Yb}$ & 99 & 96 & 94 & 91 \\
$\mathrm{Lu}$ & 100 & 95 & 92 & 89 \\
$\mathrm{Y}$ & 99 & 95 & 93 & 91 \\
$\mathrm{Sc}$ & 100 & 96 & 93 & 92
\end{tabular}

the $\mathrm{Fe}-\mathrm{O}$ stretching band underwent a relative decrease. Secondly, after the $\mathrm{SiO}_{2}$ layer was coated, peaks appeared at $1089 \mathrm{~cm}^{-1}$, which were attributed to the stretching vibrations of Si-O-Si bonds. Thirdly, after the final modification with DODGA, the appearance of two new peaks at $1730 \mathrm{~cm}^{-1}$ and $2955 \mathrm{~cm}^{-1}$ confirmed that DODGA was successfully covalently bonded to the surface of $\mathrm{Fe}_{3} \mathrm{O}_{4} @ \mathrm{mSiO}_{2}$, and these were attributed to the stretching vibrations of $\mathrm{C}=\mathrm{O}$ and $\mathrm{C}-\mathrm{H}$ bonds.

To quantify the DODGA present on the chemically modified $\mathrm{Fe}_{3} \mathrm{O}_{4}$ nanoparticles, thermogravimetric analysis was used to estimate the content of DGA ligands. As shown in Fig. 2C, in the TGA curves of $\mathrm{Fe}_{3} \mathrm{O}_{4} @ \mathrm{mSiO}_{2}, \mathrm{Fe}_{3} \mathrm{O}_{4} @ \mathrm{mSiO}_{2} @ \mathrm{NH}_{2}$ and $\mathrm{Fe}_{3}$ $\mathrm{O}_{4} @ \mathrm{mSiO}_{2}$-DODGA in the temperature range of $30-750{ }^{\circ} \mathrm{C}$ there was an obvious change in the loss of mass from $\mathrm{Fe}_{3}$ $\mathrm{O}_{4} @ \mathrm{mSiO}_{2}-$ DODGA. Owing to the physical adsorption of water by $\mathrm{Fe}_{3} \mathrm{O}_{4} @ \mathrm{mSiO}_{2}$, there was a slight mass loss during the heating process. At $750{ }^{\circ} \mathrm{C}$, the weight loss for $\mathrm{Fe}_{3} \mathrm{O}_{4} @ \mathrm{mSiO}_{2}$ was $0.31 \mathrm{wt} \%$. After the modification with amino groups and DODGA ligands of the surface of the magnetic nanoparticles, an obvious weight loss was detected. DODGA on the nanoparticles began to decompose thermally at about $200{ }^{\circ} \mathrm{C}$. This process did not stop until the temperature reached $500{ }^{\circ} \mathrm{C}$. Finally, the weight loss for $\mathrm{Fe}_{3} \mathrm{O}_{4} @ \mathrm{mSiO}_{2}-$ DODGA at $750{ }^{\circ} \mathrm{C}$ reached $21.3 \%$, whereas the weight loss for $\mathrm{Fe}_{3} \mathrm{O}_{4} @ \mathrm{mSiO}_{2} @ \mathrm{NH}_{2}$ was $8.2 \%$. According to the results of the TGA analysis, the weight percentage of DODGA on the modified nanoparticles was about $13.1 \%$, which indicated that the content of the DODGA ligand on the modified adsorbent was approximately $367 \mu \mathrm{mol} \mathrm{g}^{-1}$.

The magnetic properties of magnetic nanoparticles are an important aspect of their properties and ensure the rapid separation of adsorbents from a complex matrix. VSM was utilized to investigate the magnetic properties of $\mathrm{Fe}_{3} \mathrm{O}_{4}, \mathrm{Fe}_{3}$ $\mathrm{O}_{4} @ \mathrm{mSiO}_{2}$ and $\mathrm{Fe}_{3} \mathrm{O}_{4} @ \mathrm{mSiO}_{2}$-DODGA nanoparticles. As shown in Fig. 2D, because it was coated with $\mathrm{SiO}_{2}$ and DODGA layers the saturation magnetization of $\mathrm{Fe}_{3} \mathrm{O}_{4}$ decreased from the initial value of $58.5 \mathrm{emu} \mathrm{g}^{-1}$ to $37.3 \mathrm{emu} \mathrm{g}^{-1}$. This result for the magnetic response of $\mathrm{Fe}_{3} \mathrm{O}_{4} @ \mathrm{mSiO}_{2}$-DODGA nanoparticles showed that they still possessed high magnetization and could

Table 3 Tolerance limits for coexisting ions

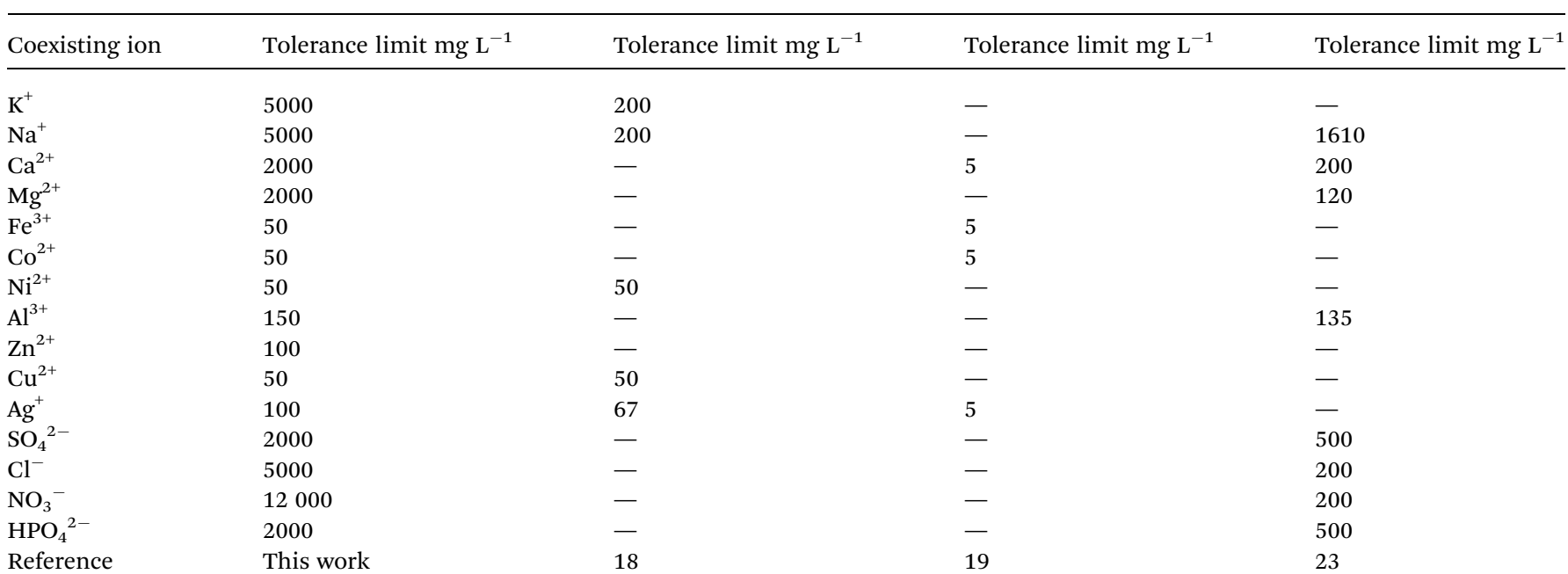




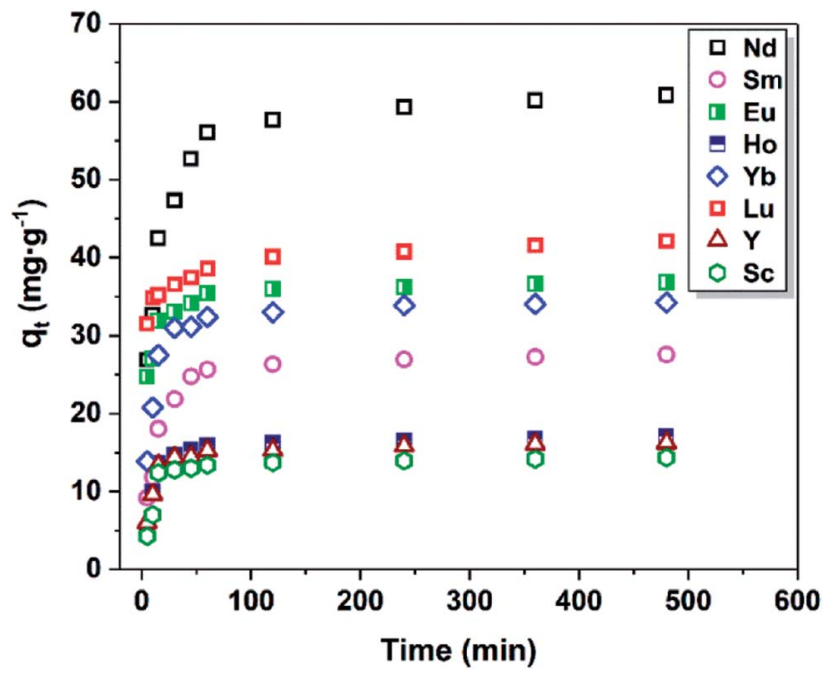

Fig. 6 Adsorption kinetics of 8 REEs.

be rapidly and completely separated from the mixture by an external magnetic field within $30 \mathrm{~s}$. These three kinds of nanoparticle displayed no magnetic hysteresis and exhibited superparamagnetic behaviour, which made them disperse homogeneously without an external magnet and aggregate quickly in the presence of a magnet during practical applications.

\subsection{Adsorption experiments}

The material, namely, $\mathrm{Fe}_{3} \mathrm{O}_{4} @ \mathrm{mSiO}_{2}$-DODGA, that was prepared and used in this study displayed some advantages over former materials. Firstly, magnetic $\mathrm{Fe}_{3} \mathrm{O}_{4}$ particles were chosen as the inner supporting core. Their excellent superparamagnetic characteristics were beneficial for their rapid collection from real samples. Secondly, the nanosized dimensions of this material guaranteed a large specific surface area for chemical modification for further anchoring the functional ligand DODGA. Thirdly, DODGA, which has a high coordination ability for REEs, was chemically bonded to the $\mathrm{Fe}_{3} \mathrm{O}_{4}$ particles to create a bifunctional adsorbent.

3.2.1 Effects of the concentration of $\mathrm{HNO}_{3}$. The nitric acid concentration affected the formation of metal chelates and played an essential role in the adsorption of REEs on $\mathrm{Fe}_{3} \mathrm{O}_{4}$ @$\mathrm{mSiO}_{2}$-DODGA.

The adsorption rate (AR\%) was calculated by:

$$
\mathrm{AR} \%=\left(C_{0}-C_{\mathrm{e}}\right) \times 100 / C_{0}
$$

where $C_{0}$ and $C_{\mathrm{e}}$ are the concentration of the REE in the aqueous phase before and after adsorption, respectively.

The adsorption results are shown in Fig. 3. When the concentration of the $\mathrm{HNO}_{3}$ solution was $0.01 \mathrm{~mol} \mathrm{~L}^{-1}$, the adsorbent displayed different adsorption capabilities for all 16 REEs. All the adsorption rates for each REE were low. With an increase in the concentration of the $\mathrm{HNO}_{3}$ solution, the adsorption rates for 15 REEs, other than Tm, all increased. The adsorption rates of $\mathrm{Fe}_{3} \mathrm{O}_{4} @ \mathrm{mSiO}_{2}$-DODGA for 9 REEs (namely, $\mathrm{Nd}, \mathrm{Sm}, \mathrm{Eu}, \mathrm{Dy}, \mathrm{Ho}, \mathrm{Yb}, \mathrm{Lu}, \mathrm{Y}$ and Sc) exceeded $80 \%$ when the concentration of the $\mathrm{HNO}_{3}$ solution was $1.0 \mathrm{~mol} \mathrm{~L}^{-1}$. However, when the concentration of nitric acid was increased to $3.0 \mathrm{~mol} \mathrm{~L}{ }^{-1}$, the increase in the adsorption rate of the $\mathrm{Fe}_{3}$ $\mathrm{O}_{4} @ \mathrm{mSiO}_{2}$-DODGA nanoparticles for 9 rare earth elements was

Table 4 Equations of the kinetic models

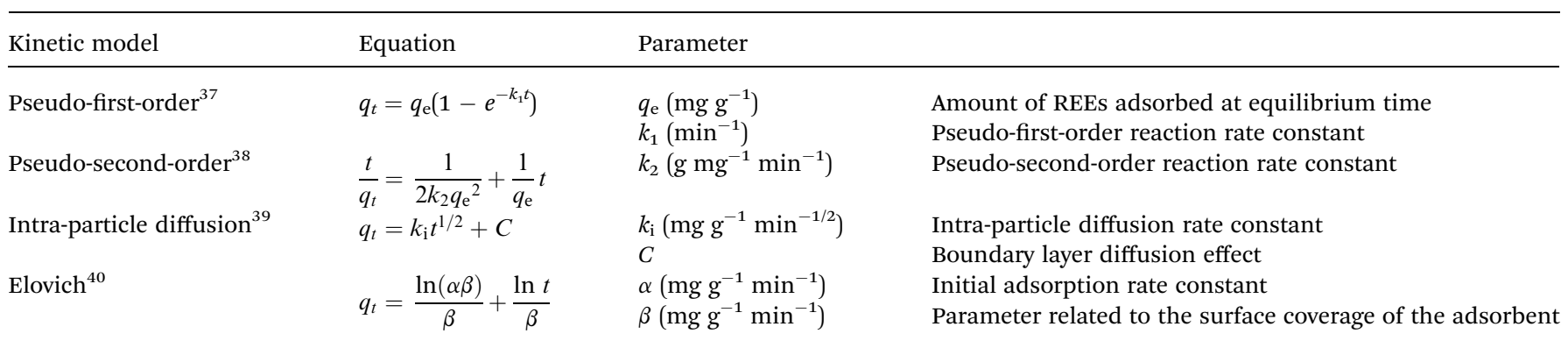

Table 5 Parameters of pseudo-first-order and pseudo-second-order models

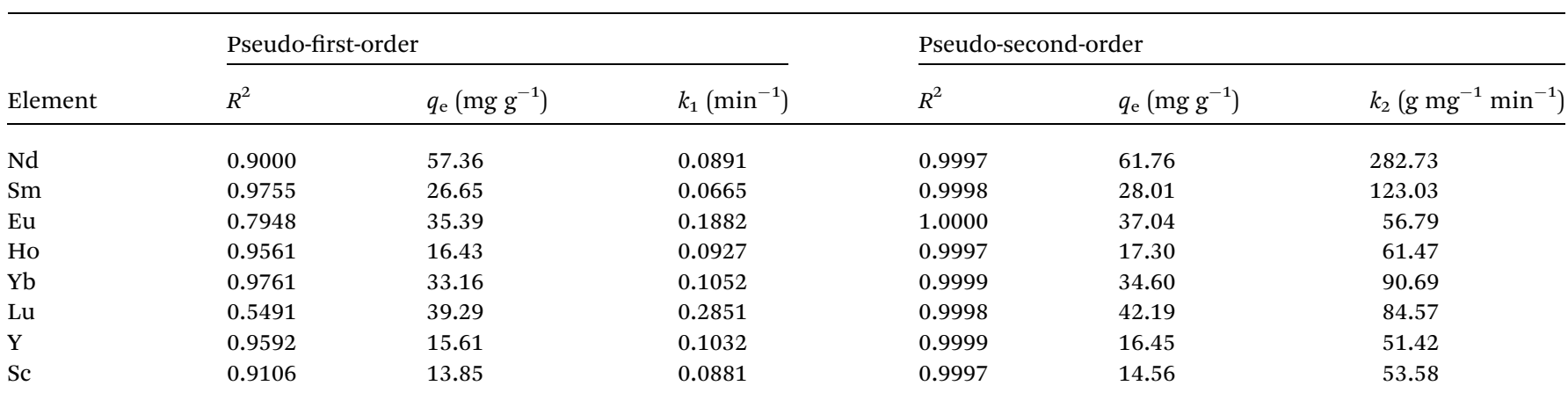


Table 6 Parameters of intra-particle diffusion and Elovich models

\begin{tabular}{|c|c|c|c|c|c|c|}
\hline \multirow[b]{2}{*}{ Element } & \multicolumn{3}{|c|}{ Intra-particle diffusion } & \multicolumn{3}{|l|}{ Elovich } \\
\hline & $R^{2}$ & $k_{\mathrm{i}}\left(\mathrm{mg} \mathrm{g}^{-1} \min ^{-1 / 2}\right)$ & $C$ & $R^{2}$ & $\begin{array}{l}\alpha \\
\left(\mathrm{mg} \mathrm{g}^{-1} \min ^{-1}\right)\end{array}$ & $\beta\left(\mathrm{mg} \mathrm{g}^{-1} \min ^{-1}\right)$ \\
\hline Nd & 0.6592 & 1.4109 & 35.99 & 0.9612 & 45.6711 & 0.03711 \\
\hline $\mathrm{Sm}$ & 0.5851 & 0.7398 & 14.79 & 0.9266 & 17.5533 & 0.06792 \\
\hline $\mathrm{Eu}$ & 0.5898 & 0.4675 & 28.68 & 0.9298 & 89.1700 & 0.10771 \\
\hline $\mathrm{Lu}$ & 0.8311 & 0.4466 & 33.57 & 0.9867 & 284.1745 & 0.12994 \\
\hline Y & 0.4985 & 0.3384 & 10.42 & 0.8782 & 13.1118 & 0.14076 \\
\hline Sc & 0.4386 & 0.3277 & 8.76 & 0.8181 & 13.0943 & 0.14125 \\
\hline
\end{tabular}

not obvious. During the adsorption procedure, a high concentration of $\mathrm{HNO}_{3}$ could potentially cause damage to instruments. Therefore, a $2.0 \mathrm{~mol} \mathrm{~L}^{-1} \mathrm{HNO}_{3}$ solution was used in the following adsorption experiments. In these conditions, the adsorption rates for all 16 rare earth elements ranged from $17.3 \%$ to $100.1 \%$ (Table 1). Among these elements, the adsorption rates for $\mathrm{Nd}, \mathrm{Sm}, \mathrm{Eu}, \mathrm{Dy}, \mathrm{Ho}, \mathrm{Yb}, \mathrm{Lu}, \mathrm{Y}$ and Sc ranged from $85.12 \%$ to $100.10 \%$.

Moreover, the ligand has two carbonyl groups and an ether bond of which the oxygen atoms donate electrons to REE ions. It has been reported that ${ }^{47}$ nitrogen donor ligands have higher coordination affinities for trivalent actinide ions in comparison with trivalent lanthanide ions. The adsorption results shown in Table 1 are in agreement with the above conclusion. Furthermore, according to the literature ${ }^{\mathbf{4 8 , 4 9}}$ cited in the above research article, DODGA exhibited different adsorption behaviour for REEs when it was used in liquid-liquid extraction. As the functional ligand for the adsorption of REEs, the anchoring of DODGA on $\mathrm{Fe}_{3} \mathrm{O}_{4} @ \mathrm{mSiO}_{2}$-DODGA made it display the same adsorption properties. The difference in the amount of each REE adsorbed by $\mathrm{Fe}_{3} \mathrm{O}_{4} @ \mathrm{mSiO}_{2}$-DODGA proved the above conclusion. Moreover, when each REE had the same
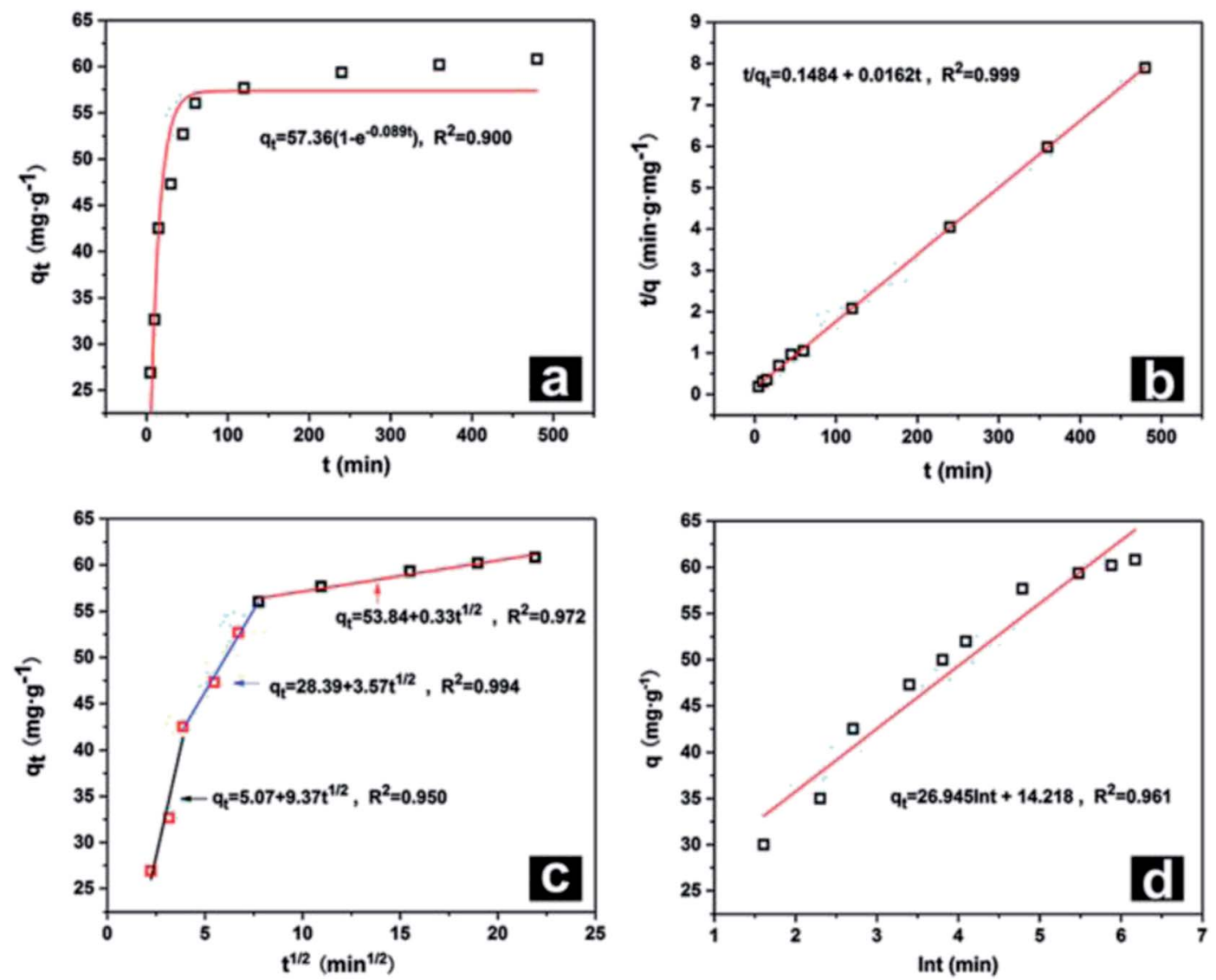

Fig. 7 Kinetic plots for $\mathrm{Nd}$ as a representative element: (a) pseudo-first-order, (b) pseudo-second-order, (c) intra-particle diffusion, and (d) Elovich models. 
concentration in the solution, the adsorption behaviour of each REE on $\mathrm{Fe}_{3} \mathrm{O}_{4} @ \mathrm{mSiO}_{2}$-DODGA was competitive. In particular, if the same amount of $\mathrm{Fe}_{3} \mathrm{O}_{4} @ \mathrm{mSiO}_{2}$-DODGA was used for adsorption, the amount of each REE adsorbed was different.

3.2.2 Effects of EDTA concentration on desorption rate. The REEs adsorbed on the $\mathrm{Fe}_{3} \mathrm{O}_{4} @ \mathrm{mSiO}_{2}$-DODGA nanoparticles were recovered by eluting the nanoparticles with an EDTA solution.

The desorption rate (DR\%) was calculated by:

$$
\mathrm{DR} \%=C_{\mathrm{d}} \times 100 /\left(C_{0}-C_{\mathrm{e}}\right)
$$

where $C_{\mathrm{d}}, C_{0}$ and $C_{\mathrm{e}}$ are the concentration of the REE eluted from $\mathrm{Fe}_{3} \mathrm{O}_{4} @ \mathrm{mSiO}_{2}-$ DODGA and the concentrations of the REE in the aqueous phase before and after adsorption, respectively.

As shown in Fig. 4, when the concentration of EDTA was $0.01 \mathrm{~mol} \mathrm{~L}^{-1}$ the desorption rate for each REE ion reached its maximum value. The desorption rates for some REEs (namely, $\mathrm{Nd}, \mathrm{Ce}, \mathrm{Sm}, \mathrm{Eu}, \mathrm{Ho}, \mathrm{Yb}, \mathrm{Lu}, \mathrm{Y}$, and Sc) were greater than $85 \%$ (Table 1). When the concentration of EDTA continued to increase, the desorption rates for the REEs decreased. Therefore, $0.01 \mathrm{~mol} \mathrm{~L}^{-1}$ EDTA was selected as the optimal concentration in the following experiments.

3.2.3 Stability of $\mathrm{Fe}_{3} \mathrm{O}_{4} @ \mathrm{mSiO}_{2}$-DODGA in $\mathrm{HNO}_{3}$. To determine whether the $\mathrm{Fe}_{3} \mathrm{O}_{4} @ \mathrm{mSiO}_{2}$-DODGA nanoparticles could withstand contact with $\mathrm{HNO}_{3}$ for the adsorption of REEs, the relative stability of $\mathrm{Fe}_{3} \mathrm{O}_{4} @ \mathrm{mSiO}_{2}$-DODGA in an $\mathrm{HNO}_{3}$ solution was investigated. $\mathrm{Fe}_{3} \mathrm{O}_{4} @ \mathrm{mSiO}_{2}$-DODGA nanoparticles were immersed in an $\mathrm{HNO}_{3}$ solution with a concentration of $2 \mathrm{~mol} \mathrm{~L}^{-1}$ for different times (1, 2, and 3 days). Then, their adsorption capacities for REEs were tested. As shown in Fig. 5, after 3 days the adsorption rate did not decrease significantly, which implied that $\mathrm{Fe}_{3} \mathrm{O}_{4} @ \mathrm{mSiO}_{2}$-DODGA retained its adsorption ability. This also indicated that $\mathrm{Fe}_{3} \mathrm{O}_{4} @ \mathrm{mSiO}_{2}-$ DODGA was stable after long-term contact with $2 \mathrm{~mol} \mathrm{~L}^{-1} \mathrm{HNO}_{3}$ and could hence be used for the adsorption of rare earth elements in a strongly acidic environment.

3.2.4 Reusability of $\mathrm{Fe}_{3} \mathrm{O}_{4} @ \mathrm{mSiO}_{2}$-DODGA for adsorption of REEs. After the stability of $\mathrm{Fe}_{3} \mathrm{O}_{4} @ \mathrm{mSiO}_{2}-$ DODGA nanoparticles was tested, their reusability was also examined. The adsorbent was regenerated with $0.01 \mathrm{~mol} \mathrm{~L}^{-1}$ EDTA 4 times, and the adsorption effect after regeneration was expressed as a percentage of the original adsorption rate. As shown in Table 2 , after 4 adsorption-desorption cycles the $\mathrm{Fe}_{3} \mathrm{O}_{4} @ \mathrm{mSiO}_{2}-$ DODGA nanoparticles retained $88.25-92.63 \%$ of their initial adsorption rate for REEs.

Several kinds of material used for recycling REEs are listed in Table S10. $\dagger$ The materials prepared with magnetic particles as the inner core and a functional ligand are usually employed for recycling one or two kinds of REE ion. After being used for 5 or more cycles, these materials still exhibited high adsorption abilities for REE ions, whereas $\mathrm{Fe}_{3} \mathrm{O}_{4} @ \mathrm{mSiO}_{2}$-DODGA displayed great advantages over these materials.

3.2.5 Effects of coexisting ions on adsorption of REEs. Coexisting ions are ubiquitous in real sample systems and might have a negative effect on the adsorption of REEs. The effects of coexisting cations and anions on the adsorption of
Table 7 Comparison of the adsorption capacities of $\mathrm{Fe}_{3} \mathrm{O}_{4} \mathrm{amSiO}_{2}-$ DODGA for REEs with those of other magnetic adsorbents

\begin{tabular}{|c|c|c|c|}
\hline MSPE material & Element & $Q_{\max }\left(\operatorname{mg} \mathrm{g}^{-1}\right)$ & Reference \\
\hline SBA-15-BSEA-Fe ${ }_{3} \mathrm{O}_{4}$-NPS & $\mathrm{Ce}(\mathrm{III})$ & 49.00 & 18 \\
\hline $\mathrm{Fe}_{3} \mathrm{O}_{4} @ S B A-15-\mathrm{Ce}(\mathrm{III})-\mathrm{IIP}$ & Ce(III) & 87.42 & 19 \\
\hline $\mathrm{Fe}_{3} \mathrm{O}_{4} @ \mathrm{CMC}$ & $\operatorname{Eu}($ III) & 42.24 & 20 \\
\hline $\mathrm{Fe}_{3} \mathrm{O}_{4} /$ sepiolite & $\mathrm{Eu}(\mathrm{III})$ & 30.85 & 21 \\
\hline $\mathrm{Fe}_{3} \mathrm{O}_{4} @ \mathrm{CD}-\mathrm{MCs}$ & $\mathrm{Eu}(\mathrm{III})$ & 12.69 & 22 \\
\hline $\mathrm{Fe}_{3} \mathrm{O}_{4} @ \mathrm{HA}-\mathrm{MNPs}$ & Eu(III) & 10.56 & 23 \\
\hline Fe@CS-DGA & $\mathrm{Pb}(\mathrm{II})$ & 70.57 & 28 \\
\hline $\mathrm{Fe}_{3} \mathrm{O}_{4} @ \mathrm{MC}-\mathrm{DGA}$ & Am(III) & - & 29 \\
\hline \multirow[t]{2}{*}{$\mathrm{Fe}_{3} \mathrm{O}_{4} @ T O D G A$} & $\operatorname{Am}(\mathrm{III})$ & - & 30 \\
\hline & $\mathrm{Pu}(\mathrm{IV})$ & - & \\
\hline \multirow[t]{8}{*}{$\mathrm{Fe}_{3} \mathrm{O}_{4} @ \mathrm{mSiO}_{2}-\mathrm{DODGA}$} & $\mathrm{Nd}(\mathrm{III})$ & 60.80 & This work \\
\hline & $\mathrm{Sm}(\mathrm{III})$ & 27.54 & \\
\hline & Eu(III) & 36.86 & \\
\hline & Ho(III) & 17.16 & \\
\hline & Yb(III) & 34.36 & \\
\hline & Lu(III) & 42.15 & \\
\hline & $\mathrm{Y}(\mathrm{III})$ & 16.29 & \\
\hline & $\mathrm{Sc}(\mathrm{III})$ & 14.28 & \\
\hline
\end{tabular}

REEs were investigated. The effects of fifteen kinds of ion (namely, $\mathrm{K}^{+}, \mathrm{Na}^{+}, \mathrm{Ca}^{2+}, \mathrm{Mg}^{2+}, \mathrm{Fe}^{3+}, \mathrm{Co}^{2+}, \mathrm{Ni}^{2+}, \mathrm{Al}^{3+}, \mathrm{Zn}^{2+}, \mathrm{Cu}^{2+}$, $\mathrm{Ag}^{+}, \mathrm{SO}_{4}{ }^{2-}, \mathrm{Cl}^{-}, \mathrm{NO}_{3}{ }^{-}$, and $\mathrm{HPO}_{4}{ }^{2-}$ ) on the adsorption capacity were investigated. If the content of a coexisting ion was not higher than the value in Table 3, the adsorption of REEs by these nanoparticles would not be affected. By comparison with the concentrations of coexisting ions in other works, ${ }^{18,19,23}$ it was obvious that the $\mathrm{Fe}_{3} \mathrm{O}_{4} @ \mathrm{mSiO}_{2}$-DODGA nanoparticles had excellent anti-interference abilities and the potential to adsorb rare earth ions in complex samples.

3.2.6 Adsorption kinetics. Considering both the adsorption rate and the desorption rate of $\mathrm{Fe}_{3} \mathrm{O}_{4} @ \mathrm{mSiO}_{2}$-DODGA for all 16 REEs, the nanoparticles exhibited a high binding capacity for 8 rare earth ions ( $\mathrm{Nd}, \mathrm{Sm}, \mathrm{Eu}, \mathrm{Ho}, \mathrm{Yb}, \mathrm{Lu}, \mathrm{Y}$ and $\mathrm{Sc}$ ), and could be regenerated easily when EDTA was used as the eluent. Therefore, these 8 REEs were selected for use in the following adsorption kinetics and adsorption isotherm experiments.

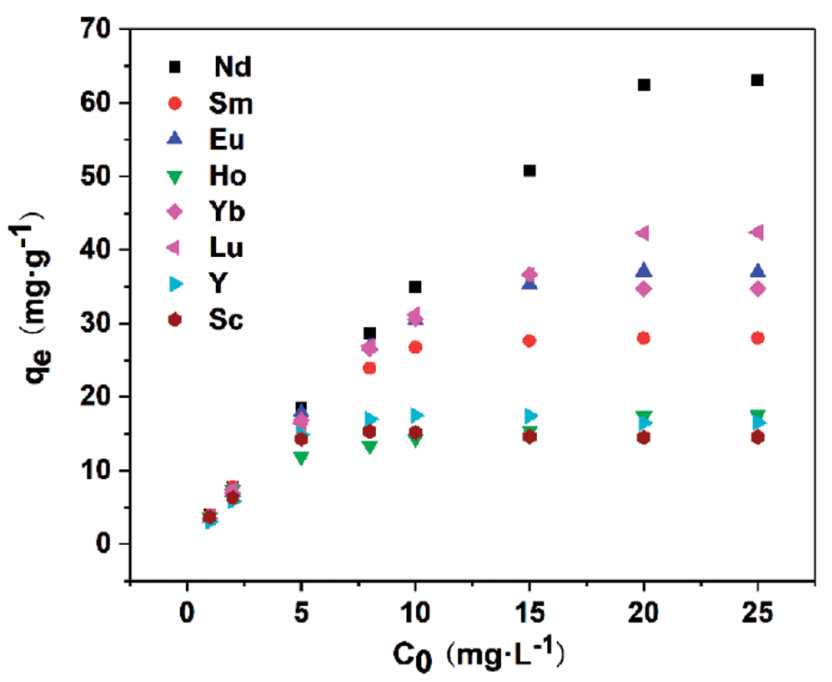

Fig. 8 Adsorption isotherms for the adsorption of REEs on $\mathrm{Fe}_{3} \mathrm{O}_{4}$ (a$\mathrm{mSiO}_{2}$-DODGA. 
Table 8 Equations of the adsorption isotherm models

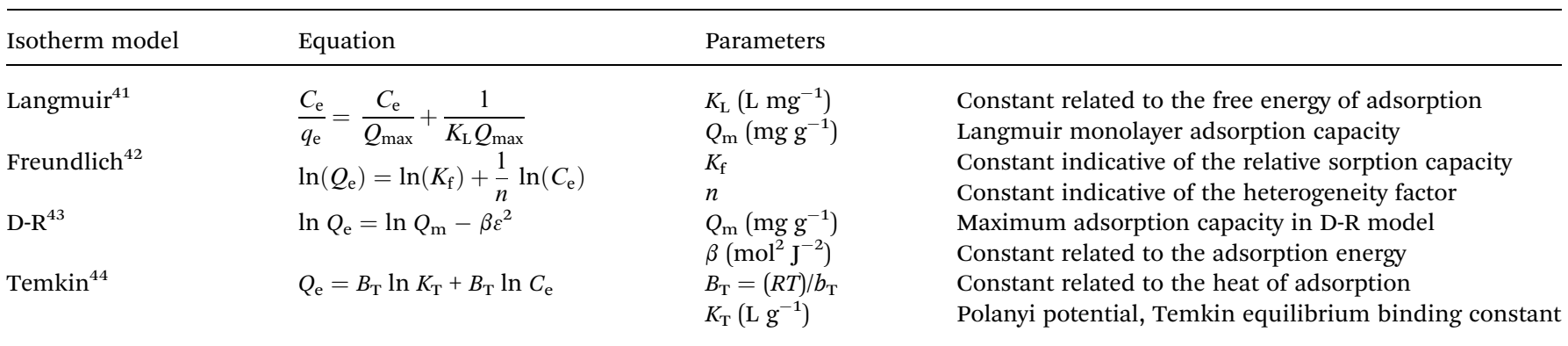

The adsorption rate of a material for REEs is commonly considered to be an important criterion for evaluating potential applications of the adsorbent. The adsorption capacity $(Q, \mathrm{mg}$ $\left.\mathrm{g}^{-1}\right)$ and the equilibrium adsorption capacity $\left(Q_{e}, \mathrm{mg} \mathrm{g}^{-1}\right)$ were calculated according to the following equation:

$$
Q=\frac{\left(C_{0}-C_{t}\right) V}{m}
$$

where $C_{0}\left(\mathrm{mg} \mathrm{L}^{-1}\right)$ is the initial concentration of REEs in the aqueous phase; $C_{t}\left(\mathrm{mg} \mathrm{L}^{-1}\right)$ is the initial and remaining concentration of REEs in the aqueous phase at different sampling intervals; $V(\mathrm{~L})$ is the volume of the solution; and $m(\mathrm{~g})$ is the weight of the adsorbent.

As shown in Fig. 6, the adsorption of REEs by $\mathrm{Fe}_{3} \mathrm{O}_{4} @ \mathrm{mSiO}_{2}-$ DODGA could reach adsorption equilibrium in $100 \mathrm{~min}$. It could be calculated that the maximum adsorption capacity of $\mathrm{Fe}_{3} \mathrm{O}_{4} @ \mathrm{mSiO}_{2}$-DODGA was 60.80, 27.54, 36.86, 17.16, 34.36, $42.15,16.29$, and $14.28 \mathrm{mg} \mathrm{g}^{-1}$ for $\mathrm{Nd}, \mathrm{Sm}, \mathrm{Eu}, \mathrm{Ho}, \mathrm{Yb}, \mathrm{Lu}, \mathrm{Y}$, and Sc, respectively.

On the basis of the data that were obtained, four kinetic models were used to analyze the adsorption behaviour of $\mathrm{Fe}_{3}$ $\mathrm{O}_{4} @ \mathrm{mSiO}_{2}$-DODGA for the 8 REEs. According to the equations in Table 4, the original data were processed and fitted. The corresponding kinetic constants, equilibrium capacities, and correlation coefficients of each adsorption kinetics model are listed in Tables 5 and 6, and the kinetic model equations are listed in the ESI (Tables S1-S4†).

Kinetics plots were obtained by taking $\mathrm{Nd}$ as a representative element and are shown in Fig. 7. The pseudo-first-order kinetic model and pseudo-second-order model indicated that adsorption was determined by diffusion and chemical adsorption, respectively. Because the value of $R^{2}$ of the pseudo-second-order model for each REE was 0.999 , this model was a better fit than the pseudo-first-order kinetic model. This result indicated that the adsorption of the 8 REEs on the $\mathrm{Fe}_{3} \mathrm{O}_{4} @ \mathrm{mSiO}_{2}$-DODGA nanoparticles mainly occurred in two ways, i.e., physical and chemical adsorption. Chemical adsorption determined the adsorption process.

After data processing according to the intra-particle diffusion kinetic model, the plot displayed three typical linear relationships. Each linear relationship corresponded to a stage of the adsorption process. The first stage was surface diffusion, which explained the diffusion of REEs from the solution to the surface of $\mathrm{Fe}_{3} \mathrm{O}_{4} @ \mathrm{mSiO}_{2}$-DODGA. The second stage was intraparticle diffusion of REEs between the $\mathrm{Fe}_{3} \mathrm{O}_{4} @ \mathrm{mSiO}_{2}$-DODGA nanoparticles. The third stage was retention of the adsorbate on the active sites, which was considered to be a stage of instantaneous entrapment. This stage could be regarded as negligible.

The Elovich model was used to describe the adsorption process on the surface of a non-uniform solid, which was based on the theoretical assumption that adsorption increased exponentially with the number of adsorption sites, which described the kinetics of a chemical adsorption process. The value of $R^{2}$ of this model was about 0.900 , which indicated that the adsorption process of REEs tended to comprise chemical adsorption on an uneven surface, which was consistent with the structural characteristics of the mesoporous layer of nanoparticles.

The adsorption capacity of $\mathrm{Fe}_{3} \mathrm{O}_{4} @ \mathrm{mSiO}_{2}$-DODGA for REEs was mainly reflected by the adsorbed amount. The total amount of REEs adsorbed by the material was $249.44 \mathrm{mg} \mathrm{g}^{-1}$ (Table 7). The highest adsorbed amount for a single REE was $60.8 \mathrm{mg} \mathrm{g}^{-1}$ for $\mathrm{Nd}(\mathrm{III})$, which was close to the reported amount. ${ }^{28}$ Other reported magnetic nanomaterials were used for the adsorption of single rare earth elements, usually Eu or Ce. In this study, the diglycolamide ligand was used to modify the magnetic nanomaterials for the further investigation of the adsorption properties for all 16 REEs and the adsorption kinetics of 8 REEs. The maximum adsorption capacities $\left(Q_{\max }\right)$ for $8 \mathrm{REEs}$ of $\mathrm{Fe}_{3} \mathrm{O}_{4} @ \mathrm{mSiO}_{2}$-DODGA in a $2 \mathrm{~mol} \mathrm{~L}^{-1}$ nitric acid solution are listed in Table 7. As shown, $Q_{\max }$ for $\mathrm{Eu}(\mathrm{III})$ was $36.86 \mathrm{mg} \mathrm{g}^{-1}$. This value is higher than those of a series of adsorbent materials such as an $\mathrm{Fe}_{3} \mathrm{O}_{4} /$ sepiolite composite, ${ }^{21}$ $\begin{array}{llll}\mathrm{Fe}_{3} \mathrm{O}_{4} @ \mathrm{CD}-\mathrm{MCs}^{22} & \text { and } & \mathrm{Fe}_{3} \mathrm{O}_{4} @ \mathrm{HA}-\mathrm{MNPs}{ }^{23} & \mathrm{Fe}_{3} \mathrm{O}_{4} @ \mathrm{mSiO}_{2}{ }^{-}\end{array}$ DODGA could be used as an effective adsorbent for the adsorption of REEs.

Table 9 Isotherm parameters of Langmuir and Freundlich models for the adsorption of REEs onto $\mathrm{Fe}_{3} \mathrm{O}_{4} \mathrm{amSiO}_{2}-$ DODGA

\begin{tabular}{|c|c|c|c|c|c|c|}
\hline \multirow[b]{2}{*}{ Element } & \multicolumn{3}{|c|}{ Langmuir } & \multicolumn{3}{|c|}{ Freundlich } \\
\hline & $R^{2}$ & $Q_{\max }\left(\mathrm{mg} \mathrm{g}^{-1}\right)$ & $K_{\mathrm{L}}\left(\mathrm{L} \mathrm{mg}^{-1}\right)$ & $R^{2}$ & $K_{\mathrm{f}}$ & $n$ \\
\hline $\mathrm{Nd}$ & 0.9327 & 68.96 & 1.33 & 0.9972 & 31.79 & 2.18 \\
\hline $\mathrm{Sm}$ & 0.9987 & 28.57 & 3.43 & 0.9366 & 16.31 & 3.40 \\
\hline $\mathrm{Eu}$ & 0.9981 & 40.16 & 1.18 & 0.9838 & 26.21 & 6.48 \\
\hline Ho & 0.9892 & 17.27 & 1.31 & 0.9950 & 10.27 & 5.53 \\
\hline $\mathrm{Yb}$ & 0.9911 & 38.75 & 1.09 & 0.9828 & 18.55 & 1.29 \\
\hline $\mathrm{Lu}$ & 0.9900 & 45.45 & 0.99 & 0.9444 & 17.60 & 2.06 \\
\hline $\mathrm{Y}$ & 0.9919 & 17.60 & 1.78 & 0.9025 & 8.83 & 1.52 \\
\hline $\mathrm{Sc}$ & 0.9983 & 14.83 & 6.41 & 0.9429 & 9.87 & 2.52 \\
\hline
\end{tabular}


Table 10 Isotherm parameters of D-R and Temkin models for the adsorption of REEs onto $\mathrm{Fe}_{3} \mathrm{O}_{4} \mathrm{amSiO}_{2}-\mathrm{DODGA}$

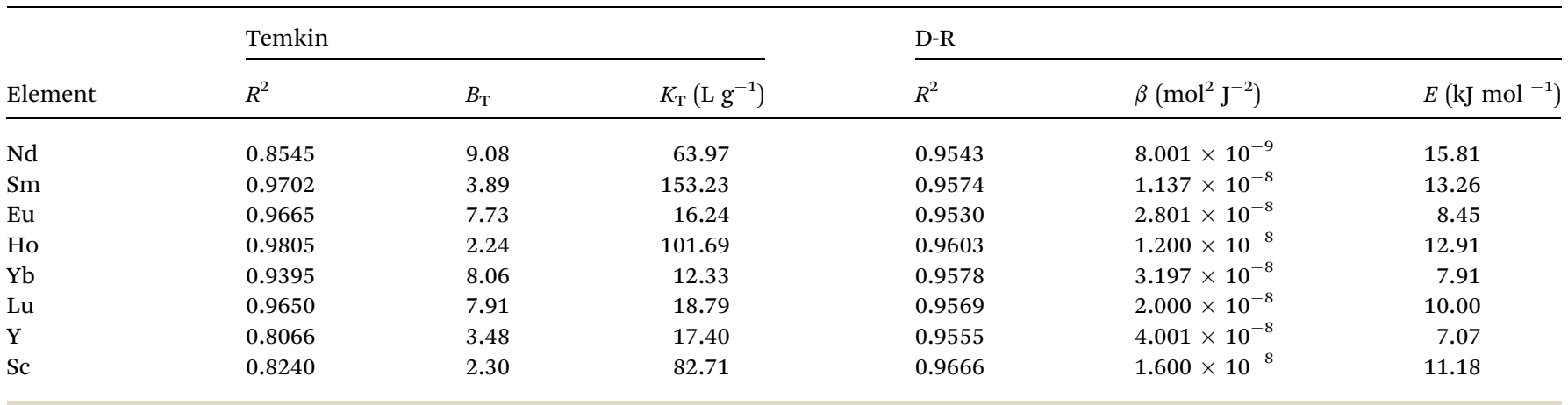

3.2.7 Adsorption isotherms. With the aim of understanding the adsorption mechanism during the adsorption process, it was necessary to carry out adsorption equilibrium experiments.

As shown in Fig. 8, the equilibrium adsorption capacity of $\mathrm{Fe}_{3} \mathrm{O}_{4} @ \mathrm{mSiO}_{2}$-DODGA for REEs increased markedly with an increase in the initial REE concentration. When the concentration of REEs was $20 \mathrm{mg} \mathrm{L}^{-1}$, the adsorption capacity reached its maximum value. This result indicated that the main driving force generated by the initial concentration of REEs could significantly affect the mass transfer of REEs from the solution to the surface of $\mathrm{Fe}_{3} \mathrm{O}_{4} @ \mathrm{mSiO}_{2}$-DODGA. Therefore, four kinds of adsorption model (Table 8, namely, Langmuir, Freundlich, Dubinin-Radushkevich (D-R) and Temkin) were utilized to quantify the adsorption capacity and investigate the specific adsorption characteristics of $\mathrm{Fe}_{3} \mathrm{O}_{4} @ \mathrm{mSiO}_{2}$-DODGA. The constants, parameters, and correlation coefficients of the 4 adsorption models are listed in Tables 9 and 10, and the kinetic model equations are listed in the ESI (Tables S5-S8 $\dagger$ ).

Upon comparing the $R^{2}$ values of the Langmuir and Freundlich models (Fig. 9), it was obvious that the adsorption data were more suitable for fitting with the Langmuir isotherm model than with the Freundlich isotherm model, which demonstrated that the adsorption of REEs by $\mathrm{Fe}_{3} \mathrm{O}_{4} @ \mathrm{mSiO}_{2}-$
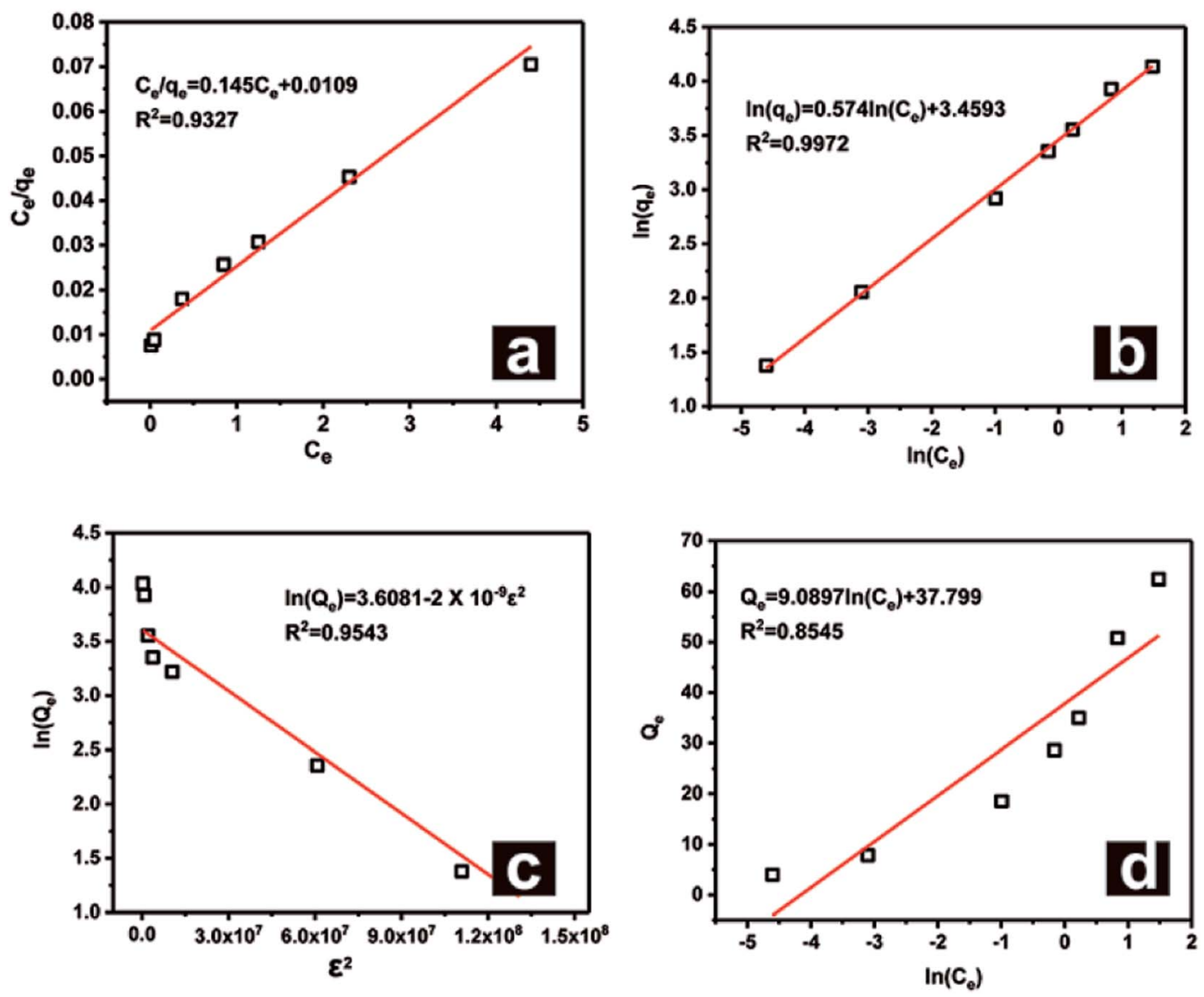

Fig. 9 Adsorption model plots for $\mathrm{Nd}$ as a representative element: (a) Langmuir, (b) Freundlich, (c) Temkin, and (d) D-R models. 
DODGA comprised single-layer adsorption. Furthermore, the Langmuir dimensionless separation factor $R_{\mathrm{L}}$ was used to predict the affinity between $\mathrm{Fe}_{3} \mathrm{O}_{4} @ \mathrm{mSiO}_{2}-$ DODGA and REEs:

$$
\mathrm{RL}=1 /\left(1+K_{\mathrm{L}} C_{0}\right)
$$

The $K_{\mathrm{L}}$ values for each REE are listed in Table S5. $\dagger$ Because all the $K_{\mathrm{L}}$ values for the 8 REEs were positive, all the $R_{\mathrm{L}}$ values were in the range of $0-1$ for all the tested REE concentrations, which indicated that the adsorption process for each REE on $\mathrm{Fe}_{3} \mathrm{O}_{4} @ \mathrm{mSiO}_{2}$-DODGA was favorable.

When the data were fitted with the D-R model, the $E$ values were obtained from this model to explain that the adsorption process was mainly dominated by chemical ion exchange or physical forces. $^{45,46}$ The $E$ values for $\mathrm{Yb}$ and $\mathrm{Y}$ were less than $8 \mathrm{~kJ} \mathrm{~mol}^{-1}$, which indicated that physical forces dominated the adsorption mechanism. The $E$ values for the other REEs were greater than $8 \mathrm{~kJ} \mathrm{~mol}^{-1}$, which suggested that chemical ion exchange was the major adsorption mechanism.

Otherwise, the Temkin isotherm model was used to process the data. The $R^{2}$ values were all greater than 0.95 . This result indicated that the binding energy distribution for each REE during the adsorption process was homogeneous. This was in agreement with the conclusion drawn from the Langmuir model.

\section{Conclusions}

In this study, magnetic mesoporous nanoparticles functionalized with the REE-adsorbing ligand DODGA were prepared. The nanoparticles of $\mathrm{Fe}_{3} \mathrm{O}_{4} @ \mathrm{mSiO}_{2}$-DODGA that were obtained were characterized by the corresponding techniques. The results showed that $\mathrm{Fe}_{3} \mathrm{O}_{4} @ \mathrm{mSiO}_{2}$-DODGA had a nanosized spherical shape and mesoporous structure, and the content of the DODGA ligand was about $367 \mu \mathrm{mol} \mathrm{g}^{-1}$. Moreover, the adsorption performance for 16 rare earth ions was measured using $\mathrm{Fe}_{3} \mathrm{O}_{4} @ \mathrm{mSiO}_{2}$-DODGA as an adsorbent. In $2 \mathrm{~mol} \mathrm{~L}^{-1}$ $\mathrm{HNO}_{3}$, the adsorption rate for the 16 rare earth ions reached its maximum value. A $0.01 \mathrm{~mol} \mathrm{~L}^{-1}$ EDTA solution was selected as the eluent to make the rare earth ions adsorbed on $\mathrm{Fe}_{3} \mathrm{O}_{4}$ @$\mathrm{mSiO}_{2}-$ DODGA undergo effective desorption. The nanoparticles were stable in $2 \mathrm{~mol} \mathrm{~L}^{-1}$ nitric acid and could be reused 5 times. Moreover, the $\mathrm{Fe}_{3} \mathrm{O}_{4} @ \mathrm{mSiO}_{2}$-DODGA nanoparticles had excellent anti-interference ability and the potential to adsorb rare earth ions in complex samples. The adsorption kinetics and adsorption isotherms of 8 rare earth ions that exhibited good performance in the adsorption and desorption experiments were investigated. An analysis of the kinetic model and adsorption isotherms indicated that the adsorption process of REEs by $\mathrm{Fe}_{3} \mathrm{O}_{4} @ \mathrm{mSiO}_{2}$-DODGA comprised single-layer adsorption via two ways, namely, physical forces and chemical adsorption. The adsorption process was controlled by chemical adsorption and also the synergistic effect of diffusion. The $\mathrm{Fe}_{3} \mathrm{O}_{4} @ \mathrm{mSiO}_{2}$-DODGA nanoparticles showed great potential for applications in the adsorption of REEs in high-salinity media.

\section{Conflicts of interest}

There are no conflicts to declare.

\section{Acknowledgements}

This work was financially supported by the National Key R\&D Program of China (No. 2017YFB0702100) and the Major Science and Technology Program for Water Pollution Control and Treatment (No. 2017ZX07402001).

\section{References}

1 S. Yasuoka, J. Ishida, K. Kishida and H. Inui, J. Power Sources, 2017, 346, 56-62.

2 X. Cao, L. Chen, S. Guo, F. Fan, R. Chen and A. Yan, Scr. Mater., 2017, 131, 24-28.

3 G. G. Peng, D. Y. Zheng, C. Cheng, J. Zhang and H. Zhang, J. Alloys Compd., 2017, 693, 1250-1256.

4 A. Rout and K. Binnemans, Dalton Trans., 2014, 43, 18621872.

5 T. V. Hoogerstraete and K. Binnemans, Green Chem., 2014, 16, 1594-1606.

6 A. Bhattacharyya, P. K. Mohapatra, T. Gadly, D. R. Raut, S. K. Ghosh and V. K. Manchanda, J. Hazard. Mater., 2011, 1951, 238-244.

7 B. Srivastava, M. K. Barman, M. Chatterjee, D. Roy and B. Mandal, J. Chromatogr. A, 2016, 1451, 1-14.

$8 \mathrm{X}$. Chen, Q. Chen, F. Guo, Y. Liao and Z. Zhao, Hydrometallurgy, 2018, 175, 326-332.

9 X. W. Huang, J. S. Dong, L. S. Wang, Z. Y. Zong, Q. N. Xue and X. L. Meng, Green Chem., 2017, 19, 1345-1352.

10 J. Liu, K. Huang, X. Wu, W. Liu, W. Song and H. Liu, Hydrometallurgy, 2018, 175, 340-347.

11 M. K. Jha, A. Kumari, R. Panda, J. R. Kumar, K. Yoo and Y. L. Jin, Hydrometallurgy, 2016, 165, 2-26.

12 D. Li, S. Egodawatte, D. I. Kaplan, S. C. Larsen, S. M. Serkiz and J. C. Seaman, J. Hazard. Mater., 2016, 317, 494-502.

13 D. Xiao, P. Dramou, N. Xiong, H. He, H. Li, D. Yuan and H. Dai, J. Chromatogr. A, 2013, 1274, 44-53.

14 Q. L. Fang, S. D. Duan, J. F. Zhang, J. X. Li and K. C. F. Leung, J. Mater. Chem. A, 2017, 5, 2947-2958.

15 J. J. Wang and J. Wei, J. Mater. Chem. A, 2017, 5, 4651-4659. 16 R. Zhou, N. F. Shen, J. Zhao, Y. Su and H. J. Ren, J. Mater. Chem. A, 2018, 6, 1275-1283.

17 J. Xu, Z. Cao, X. Liu, H. Zhao, X. Xiao, J. P. Wu, X. H. Xu and J. L. Zhou, J. Hazard. Mater., 2016, 317, 656-666.

18 K. Dashtian and R. Zaredorabei, J. Colloid Interface Sci., 2017, 494, 114-123.

19 Y. Liu, J. Qiu, Y. H. Jiang, Z. C. Liu, M. J. Meng, L. Ni, C. C. Qin and J. B. Peng, Microporous Mesoporous Mater., 2016, 234, 176-185.

20 Y. W. Cai, F. Yuan, X. M. Wang, Z. Sun, Y. Chen, Z. Y. Liu, X. K. Wang, S. T. Yang and S. A. Wang, Cellulose, 2016, 24, $1-16$.

21 S. M. Yu, X. G. Liu, G. J. Xu, Y. Qiu and L. L. Cheng, Desalin. Water Treat., 2015, 57, 1-12. 
22 Z. Q. Guo, Y. Li, S. H. Pan and J. Z. Xu, J. Mol. Liq., 2015, 206, 272-277.

23 S. T. Yang, P. F. Zong, X. M. Ren, Q. Wang and X. K. Wang, ACS Appl. Mater. Interfaces, 2012, 4, 6891-6900.

24 E. A. Mowafy and D. Mohamed, Sep. Purif. Technol., 2014, 128, 18-24.

25 K. Shimojo, K. Kurahashi and H. Naganawa, Extraction behavior of lanthanides using a diglycolamide derivative TODGA in ionic liquids, Dalton Trans., 2008, 252, 5083-5088.

26 F. K. Li, A. J. Gong, L. N. Qiu, W. W. Zhang, J. R. Li, Y. Liu, Y. N. Liu and H. T. Yuan, PLoS One, 2017, 12, e0185302.

27 H. T. Yuan, W. X. Hong, Y. S. Zhou, B. S. Pu, A. J. Gong, T. Xu, Q. S. Yang, F. K. Li, L. N. Qiu, W. W. Zhang and Y. N. Liu, J. Rare Earths, 2018, 336, 624-627.

28 R. X. Bai, Y. Zhang, Z. G. Zhao, Q. X. Liao, P. Chen, P. P. Zhao, W. H. Guo, F. Yang and L. C. Li, J. Ind. Eng. Chem., 2018, 59, 416-424.

29 S. Ojha, S. Chappa, A. M. Mhatre, K. K. Singh, V. Chavan and A. K. Pandey, J. Radioanal. Nucl. Chem., 2017, 312, 675-683.

30 V. Chavan, V. Thekkethil, A. K. Pandey, M. Iqbal, J. Huskens, S. S. Meena, A. Goswami and W. Verboom, React. Funct. Polym., 2014, 74, 52-57.

31 S. W. Cao, Y. J. Zhu and J. Chang, New J. Chem., 2008, 32, 1526-1530.

32 D. Liu, Y. Li, J. Deng and W. Yang, React. Funct. Polym., 2011, 71, 1040-1044.

33 J. P. Yang, F. Zhang, Y. R. Chen, S. Qian, P. Hu, W. Li, Y. H. Deng, Y. Fang, L. Han, M. Luqman and D. Y. Zhao, Chem. Commun., 2011, 47, 11618-11620.

34 Y. H. He, Y. Y. Huang, Y. L. Jin, X. J. Liu, G. Q. Liu and R. Zhao, ACS Appl. Mater. Interfaces, 2014, 6, 9634-9642.
35 G. Kantin, E. Chupakhin, D. Dar'in and M. Krasavin, Tetrahedron Lett., 2017, 58, 3160-3163.

36 M. Bessodes and N. Mignet, Nanotechnology for Nucleic Acid Delivery, 2013, vol. 948, pp. 67-84.

37 N. A. Oladoja, C. O. Aboluwoye and Y. B. Oladimeji, Turk. J. Eng. Environ. Sci., 2008, 32, 303-312.

38 Y. S. Ho and G. McKay, Sorption of dye from aqueous solution by peat, Chem. Eng. J., 1998, 70, 115-124.

39 M. K. Sureshkumar, D. Das, M. B. Mallia and P. C. Gupta, J. Hazard. Mater., 2010, 184, 65-72.

40 S. H. Chein and W. R. Clayton, Soil Sci. Soc. Am. J., 1980, 44, 265-268.

41 E. Repo, J. K. Warchol, T. A. Kurniawan and M. E. T. Sillanpää, Chem. Eng. J., 2010, 161, 73-82.

42 M. Jain, V. K. Garg and K. Kadirvelu, J. Hazard. Mater., 2009, 162, 365-372.

43 X. J. Hu, J. S. Wang, Y. G. Liu, X. Li, G. M. Zeng, Z. L. Bao, X. X. Zeng, A. W. Chen and F. Long, J. Hazard. Mater., 2011, 185, 306-314.

44 A. Sari and M. Tuzen, J. Hazard. Mater., 2009, 164, 10041011.

45 S. Ricodel, S. Tahaa, I. Cisseb and G. Dorange, Sep. Purif. Technol., 2001, 24, 389-401.

46 M. Arias, M. T. Barral and J. C. Mejuto, Chemosphere, 2002, 48, 1081-1088.

47 E. A. Mowafy and D. Mohamed, Sep. Purif. Technol., 2014, 128, 18-24.

48 E. A. Mowafy and H. F. Aly, Solvent Extr. Ion Exch., 2006, 24, 677-692.

49 S. A. Ansari, P. K. Mohapatra, D. R. Raut, V. C. Adya, S. K. Thulasidas and V. K. Manchanda, Sep. Purif. Technol., 2008, 63, 239-242. 